\title{
Expansion of the Candida tanzawaensis yeast clade: 16 novel Candida species from basidiocarp-feeding beetles
}

\author{
Correspondence \\ Sung-Oui Suh \\ ssuh@Isu.edu
}

\author{
Sung-Oui Suh, ${ }^{1}$ Joseph V. McHugh ${ }^{2}$ and Meredith Blackwell ${ }^{1}$ \\ 'Department of Biological Sciences, Louisiana State University, Baton Rouge, LA 70803, USA \\ ${ }^{2}$ Department of Entomology, University of Georgia, Athens, GA 30602, USA
}

A major clade of new yeast taxa from the digestive tract of basidiocarp-feeding beetles is recognized based on rRNA gene sequence analyses. Almost $30 \%$ of 650 gut isolates formed a statistically well-supported clade that included Candida tanzawaensis. The yeasts in the clade were isolated from 11 families of beetles, of which Tenebrionidae and Erotylidae were most commonly sampled. Repeated isolation of certain yeasts from the same beetle species at different times and places indicated strong host associations. Sexual reproduction was never observed in the yeasts. Based on comparisons of small- and large-subunit rRNA gene sequences and morphological and physiological traits, the yeasts were placed in Candida ambrosiae and in 16 other undescribed taxa. In this report, the novel species in the genus Candida are described and their relationships with other taxa in the Saccharomycetes are discussed. The novel species and their type strains are as follows: Candida guaymorum (NRRL $\mathrm{Y}-27568^{\top}=$ CBS $9823^{\top}$ ), Candida bokatorum (NRRL Y $-27571^{\top}=$ CBS $9824^{\top}$ ), Candida kunorum (NRRL Y $-27580^{\top}=$ CBS $9825^{\top}$ ), Candida terraborum (NRRL Y $-27573^{\top}=$ CBS $9826^{\top}$ ), Candida emberorum (NRRL Y-27606 ${ }^{\top}=$ CBS $9827^{\top}$ ), Candida wounanorum (NRRL

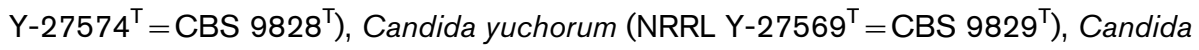
chickasaworum (NRRL Y-27566 ${ }^{\top}=$ CBS $9830^{\top}$ ), Candida choctaworum (NRRL Y-27584 $\left.=\mathrm{CBS} 9831^{\top}\right)$, Candida bolitotheri (NRRL Y-27587 ${ }^{\top}=\mathrm{CBS} 9832^{\top}$ ), Candida atakaporum $\left(\mathrm{NRRL} Y-27570^{\top}=\mathrm{CBS} 9833^{\top}\right)$, Candida panamericana $\left(\mathrm{NRRL} \mathrm{Y}-27567^{\top}=\mathrm{CBS} 9834^{\top}\right)$, Candida bribrorum (NRRL Y-27572 ${ }^{\top}=$ CBS $9835^{\top}$ ), Candida maxii (NRRL Y-27588 ${ }^{\top}$ $\left.=\mathrm{CBS} 9836^{\top}\right)$, Candida anneliseae (NRRL Y-27563 $\left.{ }^{\top}=\mathrm{CBS}_{9837^{\top}}\right)$ and Candida taliae $\left(\right.$ NRRL $Y-27589^{\top}=$ CBS $9838^{\top}$ ).

\section{INTRODUCTION}

Yeasts and yeast-like endosymbionts have been reported from a variety of insects, including planthoppers, aphids and beetles (e.g. Nardon \& Grenier, 1989; Noda \& Omura, 1992; Suh et al., 2003, 2004). Although some endosymbionts from anobiid beetles and planthoppers show an affinity to certain filamentous ascomycetes (Jones \& Blackwell, 1996; Noda et al., 1995; Noda \& Kodama, 1996; Suh et al., 2001), the majority of the fungal endosymbionts have been identified as true yeasts (Ascomycetes: Saccharomycetes) (Jones et al., 1999). We were interested in sampling insects more broadly in order to determine if associations between

Published online ahead of print on 28 June 2004 as DOI 10.1099/ ijs.0.63246-0.

Abbreviations: CT clade, Candida tanzawaensis clade; LSU, large subunit; SSU, small subunit.

The GenBank/EMBL/DDBJ accession numbers for the sequences determined in this study are listed in Table 1 and Fig. 1. additional fungi and insect hosts might be discovered. During a study of fungi from the digestive tract of basidiocarp-feeding beetles, about 650 yeasts were isolated from beetles in 26 families (Suh \& Blackwell, 2004). Based on sequence comparisons of the D1/D2 loop of the large subunit (LSU) rRNA gene used for rapid yeast characterization, about $30 \%$ of the yeast isolates formed a clade (CT clade) with Candida tanzawaensis, a yeast isolated from mosses in Japan (Nakase et al., 1988). Until the relatively recent report of six novel species (Candida ambrosiae, Candida canberraensis, Candida caryicola, Candida prunicola, Candida pyralidae and Candida xylopsoci), C. tanzawaensis had no known close relatives (Kurtzman, 2001). Currently, only one of the seven previously described species is known from multiple collections; in fact, $C$. tanzawaensis awaited description for 22 years in the vain hope that another isolate would be discovered (Nakase et al., 1988). Here, we describe 16 novel taxa, many with multiple isolates, from the gut of fungus-feeding beetles and compare the characteristics of all 23 members of the 
large CT clade, thereby recognizing unsuspected diversity in what appears to be a largely insect-associated clade.

\section{METHODS}

Yeast isolation and identification. Host beetles were collected from several different localities in Vermont, the southeastern USA, and Barro Colorado Island, Panama. Vouchers were deposited at the University of Georgia Collection of Arthropods, Athens, GA. The beetles were taken to the laboratory and usually placed in Petri dishes for 1-3 days without food prior to dissection. Surface disinfection was by submersion in $95 \%$ ethanol for $1-2 \mathrm{~min}$. The alcohol wash was followed by a $0.7 \%$ saline rinse; the rinse liquid was plated on acidified YM agar (Difco YM broth, $2 \%$ plain agar, adjusted to $\mathrm{pH} 3 \cdot 5$ with $\mathrm{HCl}$ ) as a negative control. The beetle gut was removed aseptically under a dissecting microscope and transferred to tubes containing $0 \cdot 7 \%$ saline. The gut segments were crushed in the saline solution with a pipette tip and streaked with a loop onto the surface of an acidified YM agar plate. Plates were incubated at $25^{\circ} \mathrm{C}$, and single colonies were streaked for purification. Cultures were maintained on YM agar or $2 \%$ malt extract agar (Yarrow, 1998). The isolates were initially screened and grouped using the D1/D2 loop sequence of the LSU rRNA gene. Selected isolates from each LSU genotype have been deposited at the Agricultural Research Service Culture Collection (NRRL) and Centraalbureau voor Schimmelcultures (CBS); holotype specimens were deposited at NRRL as lyophilized cultures (Table 1). The morphological observations and metabolic tests comprising the yeast standard description were performed on at least one isolate from each LSU genotype, according to established methods (Yarrow, 1998; Barnett et al., 2000). Isolates within each clade were crossed in all combinations and observed on YM agar, $2 \%$ malt agar and cornmeal agar at $17^{\circ} \mathrm{C}$ for 6 weeks in order to detect ascospore development. Brightfield microscopic examination was the usual method of observation, but some cell preparations were examined more closely with fluorescence microscopy using $0.02 \%$ Calcofluor white as an optical brightener to visualize yeast cell walls more clearly.

DNA sequencing and sequence analysis. The D1/D2 region of the LSU rRNA gene was amplified directly without DNA extraction from yeast cells. A cell suspension of one loopful of cells in $50 \mu \mathrm{l}$ of autoclaved water was heated at $95^{\circ} \mathrm{C}$ for $5 \mathrm{~min}$, and $2 \mu \mathrm{l}$ of the supernatant was used as a template in $50 \mu \mathrm{l}$ PCRs. For the small subunit (SSU) rRNA gene, the nucleic acids were extracted and purified following the procedures of Lee \& Taylor (1990). The primer sets NS1/NS8 and LS1/LR5 were used for PCR amplification of the SSU and LSU rRNA gene, respectively (White et al., 1990; Hausner et al., 1993). PCR products were purified using a DNA purification kit (Bio-Rad Laboratories), and purified double-stranded PCR products were used as templates for sequencing with an ABI PRISM BigDye Terminator cycle sequencing kit. The complete sequence of the SSU rRNA gene and the D1/D2 region of the LSU rRNA gene were obtained with the primers NS1, NS2, 18H, NS5, NS8, LS1 and LR3 using an ABI PRISM 377 automated DNA sequencer. GenBank/EMBL/DDBJ accession numbers for DNA sequences from this study are listed in Table 1 and Fig. 1. SSU rRNA gene sequences of previously described Candida species in the CT clade were determined to compare with the novel gut yeast isolates. Previously described species names and GenBank/EMBL/ DDBJ accession numbers are as follows: C. ambrosiae NRRL YB$1316^{\mathrm{T}}$ (AY227712), C. tanzawaensis NRRL Y-17324 ${ }^{\mathrm{T}}$ (AY227713), C. canberraensis NRRL YB- $2417^{\mathrm{T}}$ (AY488124), C. caryicola NRRL YB- $1499^{\mathrm{T}}$ (AY488125), C. prunicola NRRL YB-869 ${ }^{\mathrm{T}}$ (AY488126), C. pyralidae NRRL Y-27085 ${ }^{\mathrm{T}}$ (AY488127) and C. xylopsoci NRRL $\mathrm{Y}-27066^{\mathrm{T}}$ (AY488128). DNA sequences were aligned with the multi-alignment program CLUSTAL_X (Thompson et al., 1997) and optimized visually. Ambiguous regions were excluded from the analyses. Sequences from newly isolated yeasts were compared with LSU and SSU rRNA gene sequences of other yeasts and fungi obtained from GenBank. Yeast groups based on the D1/D2 sequence were designated by the first four letters of the host beetle family and a number for each unique genotype varying by one or more base pairs from other yeasts from the same beetle family. Maximumparsimony analyses were performed using PAUP* $4.0 \mathrm{~b} 10$ (Swofford, 2002). Heuristic tree searches were executed using the tree bisectionreconnection branch-swapping algorithm with random sequence analysis. Bootstrap values of the most parsimonious tree were obtained from 1000 replications. Base pair differences were counted using BLAST2 Sequences (Tatusova \& Madden, 1999) or from the manually aligned sequence database.

\section{RESULTS AND DISCUSSION}

\section{Yeast isolates in the CT clade}

We cultured about 650 yeasts from beetles in 26 families. Most of the isolates were true yeasts (Ascomycota: Saccharomycetes). Phylogenetic analysis of about $600 \mathrm{bp}$ of sequence from the D1/D2 region of the LSU rRNA gene was used for rapid identification and grouping of the isolates. We discovered a major clade consisting of about $30 \%$ of all beetle gut yeast isolates obtained using this technique. The taxa were closely related to C. tanzawaensis and six other previously described Candida species (Kurtzman, 2001). Detailed information about the 164 yeast isolates in the greatly enlarged CT clade is provided in Table 1. The gut yeasts in the CT clade were isolated from species in 11 families of beetles: Anthribidae, Carabidae, Ciidae, Endomychidae, Erotylidae, Histeridae, Melandryidae, Nitidulidae, Scarabaeidae, Staphylinidae (including Scaphidiinae) and Tenebrionidae. However, the majority of the yeasts (140 of 164 isolates, Table 1) were from species of Erotylidae and Tenebrionidae. The CT clade gut yeasts were sorted into 39 groups based on their D1/D2 genotype and host beetle ranges. Only three isolates (Erot8, Nitil4 and Tene7) had a D1/D2 genotype identical to a previously described species (C. ambrosiae). The other 36 groups were distinct from all other previously described species (Table 1).

\section{Novel species in the CT clade}

In addition to the D1/D2 region of the LSU rRNA gene sequences, complete sequences of the SSU rRNA gene (about $1750 \mathrm{bp}$ ) were determined for at least one isolate from each LSU genotype (see Table 1 for selected isolates), and these were combined with the LSU rRNA gene sequences in a dataset for better estimation of a phylogeny. A most-parsimonious tree was constructed from the combined dataset of SSU and LSU rRNA gene sequences by comparing the yeasts with taxa in Ascomycota and other yeasts alone (Fig. 1). The 39 gut yeasts we compared were representatives of the total 164 isolates in the clade (Fig. 1) with C. tanzawaensis and the other six previously described clade members. The clade was well supported statistically by $100 \%$ bootstrap value (Fig. 1). Of the seven 


\begin{tabular}{|c|c|c|c|c|c|c|c|c|}
\hline \multirow[t]{2}{*}{ Species } & \multicolumn{3}{|c|}{ Strain designation ${ }^{*}$} & \multirow{2}{*}{$\begin{array}{l}\text { LSU rRNA } \\
\text { gene groups }\end{array}$} & \multirow[t]{2}{*}{ Host beetles and place of collection ${ }^{\star}$} & \multirow{2}{*}{$\begin{array}{c}\text { Total } \\
\text { number of } \\
\text { isolates } \dagger\end{array}$} & \multicolumn{2}{|c|}{ Nucleotide differences $\ddagger$} \\
\hline & CBS & NRRL & LSU & & & & $\begin{array}{l}\text { LSU } \\
\text { rRNA gene }\end{array}$ & $\begin{array}{l}\text { SSU } \\
\text { rRNA gene }\end{array}$ \\
\hline \multirow[t]{6}{*}{ C. guaymorum } & $9823^{\mathrm{T}}$ & $\mathrm{Y}-27568^{\mathrm{T}}$ & BG 01-7-26-006B-1-1 ${ }^{\mathrm{T}}$ & Erot21 & $\begin{array}{l}\text { Mycotretus interstitialis (Erotylidae) ex imbricate } \\
\text { basidiocarp, BCI, Panama }\end{array}$ & 1 & $\mathrm{~T}$ & $\mathrm{~T}$ \\
\hline & & & BG 01-7-26-006A-2-1 & Erot21 & $\begin{array}{l}\text { Iphiclus (Habrodactylus) conspicillatus (Erotylidae) } \\
\text { ex imbricate basidiocarp, BCI, Panama }\end{array}$ & 3 & 0 & 0 \\
\hline & & & BG 02-7-16-022A-1-1 & Erot21 & $\begin{array}{l}\text { Cyclomorphus sp. (Erotylidae) ex polypore, BCI, } \\
\text { Panama }\end{array}$ & 3 & 0 & - \\
\hline & & & BG 02-7-20-020A-1-1 & Erot21 & $\begin{array}{l}\text { Iphiclus sp. (Erotylidae) ex corticioid fungus, BCI, } \\
\text { Panama }\end{array}$ & 1 & 0 & - \\
\hline & & & BG 02-7-20-020B-1-1 & Erot21 & $\begin{array}{l}\text { Cyclomorphus sp. (Erotylidae) ex corticioid fungus, } \\
\text { BCI, Panama }\end{array}$ & 1 & 0 & - \\
\hline & & Y-27581 & BG 01-7-21-003A-1-1 & Scar2 & $\begin{array}{l}\text { Onthophagus sp. (Scarabaeidae) ex Polyporus } \\
\text { tenuiculus, BCI, Panama }\end{array}$ & 1 & 0 & 0 \\
\hline \multirow[t]{9}{*}{ C. bokatorum } & $9824^{\mathrm{T}}$ & $\mathrm{Y}-27571^{\mathrm{T}}$ & BG 02-7-16-039A-2-1 ${ }^{\mathrm{T}}$ & Erot35 & $\begin{array}{l}\text { Pselaphacus signatus (Erotylidae) ex P. tenuiculus, } \\
\text { BCI, Panama }\end{array}$ & 10 & $\mathrm{~T}$ & $\mathrm{~T}$ \\
\hline & & & BG 02-7-14-001E-4-1 & Erot35 & $\begin{array}{l}\text { Mycotretus nitescens (Erotylidae) ex P. tenuiculus, } \\
\text { BCI, Panama }\end{array}$ & 2 & 0 & - \\
\hline & & & BG 02-7-16-030B-3-2 & Erot35 & $\begin{array}{l}\text { Iphiclus (Megaprotus) delineatus (Erotylidae) ex } \\
\text { corticioid fungus, BCI, Panama }\end{array}$ & 3 & 0 & - \\
\hline & & & BG 02-7-18-023B-1-2 & Erot35 & $\begin{array}{l}\text { Larva of Ellipticus gemellatus (Erotylidae) ex } \\
\text { Tinctoporellus epimiltinus, BCI, Panama }\end{array}$ & 1 & 0 & - \\
\hline & & & BG 02-7-14-001D-1-1 & Erot35 & $\begin{array}{l}\text { Pselaphacus sp. (Erotylidae) ex P. tenuiculus, BCI, } \\
\text { Panama }\end{array}$ & 1 & 0 & - \\
\hline & & Y-27558 & BG 02-7-14-001G-1-1 & Cara2 & $\begin{array}{l}\text { Unidentified carabid (Carabidae) ex P. tenuiculus, } \\
\text { BCI, Panama }\end{array}$ & 1 & 0 & 0 \\
\hline & & Y-27579 & BG 02-7-14-001F-1-1 & Niti19 & $\begin{array}{l}\text { Teichostethus testaceous (Nitidulidae) ex P. tenuiculus, } \\
\text { BCI, Panama }\end{array}$ & 2 & 0 & 0 \\
\hline & & Y-27576 & BG 02-7-14-001J-1-1 & Mela1 & $\begin{array}{l}\text { Unidentified melandryid (Melandryidae) ex } P \text {. } \\
\text { tenuiculus, BCI, Panama }\end{array}$ & 1 & 0 & 0 \\
\hline & & & BG $02-7-14-001 \mathrm{~K}-1-2$ & Tene27 & $\begin{array}{l}\text { Unidentified tenebrionid (Tenebrionidae) ex } \\
\text { P. tenuiculus, BCI, Panama }\end{array}$ & 2 & 0 & 0 \\
\hline C. kunorum & $9825^{\mathrm{T}}$ & $\mathrm{Y}-27580^{\mathrm{T}}$ & BG 02-7-18-017A-1-1 & Niti25 & $\begin{array}{l}\text { T. testaceous (Nitidulidae) ex Nodulisporium sp., BCI, } \\
\text { Panama }\end{array}$ & 1 & $\mathrm{~T}$ & $\mathrm{~T}$ \\
\hline C. terraborum & $9826^{\mathrm{T}}$ & $\mathrm{Y}-27573^{\mathrm{T}}$ & BG 02-7-15-019A-2-1 & Erot41 & $\begin{array}{l}\text { Iphiclus sedecimmaculatus (Erotylidae) ex corticioid } \\
\text { fungus, BCI, Panama }\end{array}$ & 1 & $\mathrm{~T}$ & $\mathrm{~T}$ \\
\hline
\end{tabular}


Table 1. cont.

\begin{tabular}{|c|c|c|c|c|c|c|c|c|}
\hline \multirow[t]{2}{*}{ Species } & \multicolumn{3}{|c|}{ Strain designation ${ }^{*}$} & \multirow{2}{*}{$\begin{array}{l}\text { LSU rRNA } \\
\text { gene groups }\end{array}$} & \multirow[t]{2}{*}{ Host beetles and place of collection ${ }^{\star}$} & \multirow{2}{*}{$\begin{array}{c}\text { Total } \\
\text { number of } \\
\text { isolates } \dagger\end{array}$} & \multicolumn{2}{|c|}{ Nucleotide differences $\ddagger$} \\
\hline & CBS & NRRL & LSU & & & & $\begin{array}{l}\text { LSU } \\
\text { rRNA gene }\end{array}$ & $\begin{array}{l}\text { SSU } \\
\text { rRNA gene }\end{array}$ \\
\hline \multirow{2}{*}{ C. emberorum } & & & BG 01-7-23-002A-1-1 & Erot24 & $\begin{array}{l}\text { Mycotretus scitulus (Erotylidae) ex Pleurotis sp., BCI, } \\
\text { Panama }\end{array}$ & 1 & 0 & - \\
\hline & & & BG 01-7-22-012A-1-1-1 & Endo2 & $\begin{array}{l}\text { Unidentified endomychid (Endomychidae) ex } \\
\text { Ripartitella brasiliensis, BCI, Panama }\end{array}$ & 2 & 3 & 0 \\
\hline C. yuchorum & $9829^{\mathrm{T}}$ & $\mathrm{Y}-27569^{\mathrm{T}}$ & BG 01-8-26-001A-1-1 ${ }^{\mathrm{T}}$ & Erot26 & $\begin{array}{l}\text { Tritoma atriventris (Erotylidae) ex Lepiota sp., Athens, } \\
\text { GA, USA }\end{array}$ & 3 & $\mathrm{~T}$ & $\mathrm{~T}$ \\
\hline \multirow[t]{2}{*}{ C. chickasaworum } & $9830^{\mathrm{T}}$ & Y-27566 ${ }^{\mathrm{T}}$ & BG 99-11-14-10-1-1 ${ }^{\mathrm{T}}$ & Erot9 & $\begin{array}{l}\text { Tritoma sp. (Erotylidae) ex Amanita sp., Athens, GA, } \\
\text { USA }\end{array}$ & 7 & $\mathrm{~T}$ & $\mathrm{~T}$ \\
\hline & & & BG 02-2-5-1-1 & Erot9 & $\begin{array}{l}\text { Tritoma sp. (Erotylidae) ex Pleurotus ostreatus, Baton } \\
\text { Rouge, LA, USA }\end{array}$ & 7 & 0 & - \\
\hline \multirow{5}{*}{ C. choctaworum } & & & BG 98-12-9-1-1 & Tenel & $\begin{array}{l}\text { N. bicornis (Tenebrionidae) ex F. supina, St Francisville, } \\
\text { LA, USA }\end{array}$ & 8 & 0 & 0 \\
\hline & & & BG 02-5-30-001B-1 & Tenel & $\begin{array}{l}\text { Unidentified tenebrionid (Tenebrionidae), Athens, GA, } \\
\text { USA }\end{array}$ & 7 & 0 & - \\
\hline & & Y-27559 & BG 99-2-5-7-1-1 & Ciid2 & $\begin{array}{l}\text { Ceracis curtus (Ciidae) ex F. supina, Baton Rouge, LA, } \\
\text { USA }\end{array}$ & 3 & 0 & 0 \\
\hline & & & BG 02-5-30-008B-1 & Ciid2 & Unidentified ciid (Ciidae), Athens, GA, USA & 2 & 0 & - \\
\hline & & Y-27557 & BG 02-3-29-3-1-1 & Anth2 & Euparius marmoreus (Anthribidae), Sulphur, LA, USA & 2 & 0 & 0 \\
\hline \multirow[t]{3}{*}{ C. bolitotheri } & $9832^{\mathrm{T}}$ & Y- $27587^{\mathrm{T}}$ & BG $00-8-15-1-1^{\mathrm{T}}$ & Tene11 & $\begin{array}{l}\text { Bolitotherus cornutus (Tenebrionidae) ex Ganoderma sp., } \\
\text { Athens, GA, USA }\end{array}$ & 1 & $\mathrm{~T}$ & $\mathrm{~T}$ \\
\hline & & & BG 00-7-30-1-1 & Tene11 & $\begin{array}{l}\text { B. cornutus (Tenebrionidae) ex Ganoderma sp., } \\
\text { Burlington, VT, USA }\end{array}$ & 3 & 0 & - \\
\hline & & & BG 02-3-29-2-2 & Tene11 & $\begin{array}{l}\text { B. cornutus (Tenebrionidae) ex Ganoderma sp., } \\
\text { Sulphur, LA, USA }\end{array}$ & 3 & 0 & - \\
\hline
\end{tabular}


Table 1. cont.

\begin{tabular}{|c|c|c|c|c|c|c|c|c|}
\hline \multirow[t]{2}{*}{ Species } & \multicolumn{3}{|c|}{ Strain designation ${ }^{\star}$} & \multirow{2}{*}{$\begin{array}{l}\text { LSU rRNA } \\
\text { gene groups }\end{array}$} & \multirow[t]{2}{*}{ Host beetles and place of collection ${ }^{\star}$} & \multirow{2}{*}{$\begin{array}{c}\text { Total } \\
\text { number of } \\
\text { isolates } \dagger\end{array}$} & \multicolumn{2}{|c|}{ Nucleotide differences $\ddagger$} \\
\hline & CBS & NRRL & LSU & & & & $\begin{array}{l}\text { LSU } \\
\text { rRNA gene }\end{array}$ & $\begin{array}{l}\text { SSU } \\
\text { rRNA gene }\end{array}$ \\
\hline & & Y-27562 & BG 99-8-11-1-1 & Erot3 & $\begin{array}{l}\text { Megalodacne fasciata (Erotylidae) ex Ganoderma } \\
\text { applanatum, Athens, GA, USA }\end{array}$ & 4 & 0 & 0 \\
\hline C. atakaporum & $9833^{\mathrm{T}}$ & $\mathrm{Y}-27570^{\mathrm{T}}$ & BG 02-7-21-Nhu-1-1-2 ${ }^{\mathrm{T}}$ & Erot 28 & $\begin{array}{l}\text { Triplax festiva (Erotylidae) ex Inonotus cuticularis, Baton } \\
\text { Rouge, LA, USA }\end{array}$ & 1 & $\mathrm{~T}$ & $\mathrm{~T}$ \\
\hline \multirow[t]{3}{*}{ C. panamericana } & $9834^{\mathrm{T}}$ & $\mathrm{Y}-27567^{\mathrm{T}}$ & BG 01-7-26-006B-2-1 ${ }^{\mathrm{T}}$ & Erot 20 & $\begin{array}{l}\text { M. interstitialis (Erotylidae) ex imbricate mushroom, BCI, } \\
\text { Panama }\end{array}$ & 1 & $\mathrm{~T}$ & $\mathrm{~T}$ \\
\hline & & Y-27582 & BG 01-7-26-006C-1-1 & Stap 1 & $\begin{array}{l}\text { Unidentified staphylinid (Staphylinidae) ex imbricate } \\
\text { basidiocarp, BCI, Panama }\end{array}$ & 1 & 0 & 0 \\
\hline & & Y-27590 & BG $02-5-27-1-2-4$ & Tene19 & $\begin{array}{l}\text { B. cornutus (Tenebrionidae) ex Ganoderma sp., Baton } \\
\text { Rouge, LA, USA }\end{array}$ & 1 & 1 & 0 \\
\hline \multirow[t]{7}{*}{ C. bribrorum } & $9835^{\mathrm{T}}$ & $\mathrm{Y}-27572^{\mathrm{T}}$ & BG 02-7-14-001D-3-1 ${ }^{\mathrm{T}}$ & Erot38 & $\begin{array}{l}\text { Larvae of Pselaphacus sp. (Erotylidae) ex P. tenuiculus, } \\
\text { BCI, Panama }\end{array}$ & 1 & $\mathrm{~T}$ & $\mathrm{~T}$ \\
\hline & & & BG 02-7-14-002A-2-1 & Erot38 & $\begin{array}{l}\text { Megalodacne audouini (Erotylidae) ex basidiocarp, BCI, } \\
\text { Panama }\end{array}$ & 3 & 0 & - \\
\hline & & & BG 02-7-14-002B-2-1 & Erot38 & $\begin{array}{l}\text { Pupa of Megalodacne sp. (Erotylidae) ex basidiocarp, } \\
\text { BCI, Panama }\end{array}$ & 1 & 0 & - \\
\hline & & & BG 02-7-20-004A-1-1 & Erot38 & $\begin{array}{l}\text { Megalodacne sp. (Erotylidae) ex Ganoderma sp., BCI, } \\
\text { Panama }\end{array}$ & 1 & 0 & - \\
\hline & & Y-27591 & BG 02-7-14-002E-2-1 & Tene28 & $\begin{array}{l}\text { Unidentified tenebrionid (Tenebrionidae) ex basidiocarp, } \\
\text { BCI, Panama }\end{array}$ & 2 & 0 & 0 \\
\hline & & Y-27592 & BG 02-7-14-002I-1-1 & Tene30 & $\begin{array}{l}\text { Unidentified tenebrionid (Tenebrionidae) ex basidiocarp, } \\
\text { BCI, Panama }\end{array}$ & 2 & 1 & 0 \\
\hline & & Y-27564 & BG 99-8-11-1-4-2 & Erot6 & $\begin{array}{l}\text { M. fasciata (Erotylidae) ex G. applanatum, Athens, GA, } \\
\text { USA }\end{array}$ & 1 & 2 & 1 \\
\hline C. maxii & $9836^{\mathrm{T}}$ & $\mathrm{Y}-27588^{\mathrm{T}}$ & BG 01-7-21-006A-1-1 ${ }^{\mathrm{T}}$ & Tene17 & $\begin{array}{l}\text { Unidentified tenebrionid (Tenebrionidae) ex polypore, } \\
\text { BCI, Panama }\end{array}$ & 2 & $\mathrm{~T}$ & $\mathrm{~T}$ \\
\hline \multirow[t]{4}{*}{ C. anneliseae } & $9837^{\mathrm{T}}$ & $\mathrm{Y}-27563^{\mathrm{T}}$ & BG 99-8-11-1-2-2 & Erot4 & $\begin{array}{l}\text { M. fasciata (Erotylidae) ex G. applanatum, Athens, GA, } \\
\text { USA }\end{array}$ & 2 & $\mathrm{~T}$ & $\mathrm{~T}$ \\
\hline & & & BG 02-7-21-Nhu-1-1-C & Erot4 & $\begin{array}{l}\text { T. festiva (Erotylidae) ex I. cuticularis, Baton Rouge, LA, } \\
\text { USA }\end{array}$ & 1 & 0 & - \\
\hline & & Y-27583 & BG 02-5-23-003E-5 & Stap5 & $\begin{array}{l}\text { Unidentified Scaphidiinae (Staphylinidae), Athens, GA, } \\
\text { USA }\end{array}$ & 1 & 0 & 0 \\
\hline & & Y-27585 & BG 98-9-2-2-4 & Tene4 & $\begin{array}{l}\text { Platydema ruficorne (Tenebrionidae) ex decayed polypore, } \\
\text { Baton Rouge, LA, USA }\end{array}$ & 11 & 0 & 0 \\
\hline
\end{tabular}


Table 1. cont.

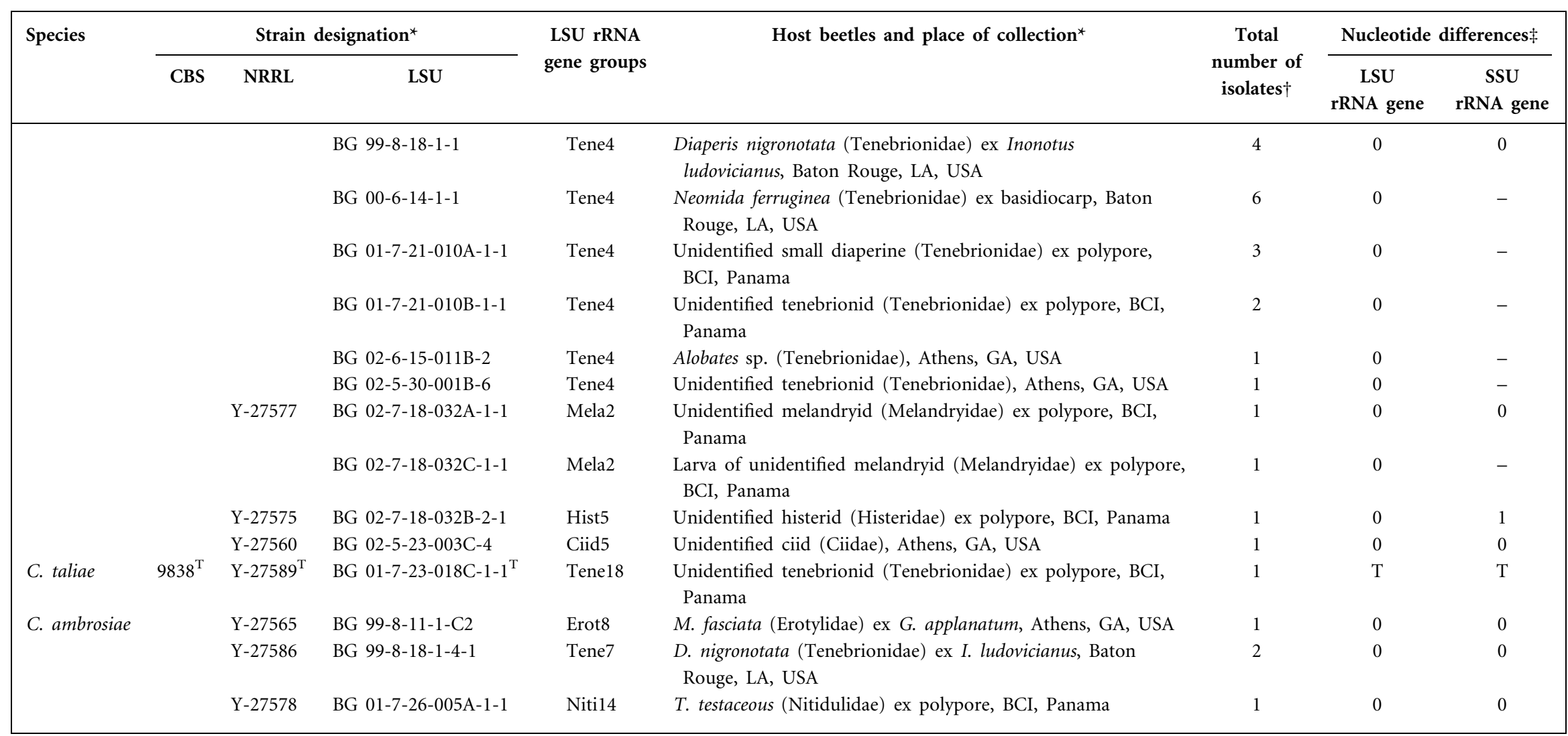

${ }^{*}$ CBS, Centraalbureau voor Schimmelcultures, Utrecht, the Netherlands; NRRL, Agricultural Research Service Culture Collection, National Center for Agricultural Utilization Research, Peoria, IL, USA; LSU, Mycology Laboratory, Department of Biological Sciences, Louisiana State University, Baton Rouge, LA, USA; BCI, Barro Colorado Island.

†Each isolate came from one beetle. Total numbers include the yeasts isolated on different collection dates.

$¥$ The D1/D2 sequences for the LSU rRNA genes were determined for all yeast isolates and deposited in GenBank/EMBL/DDBJ. Accession numbers of LSU rRNA gene sequences are AY242241, AY242244, AY242246, AY242249, AY242253, AY242254, AY242257, AY242258, AY242260, AY242262, AY242263, AY242273, AY242274, AY242277, AY242278, AY242284, AY242288, AY242298, AY242312, AY242345, AY242350-AY242352, AY309784-AY309919 and AY426946-AY426949. The sequence of the SSU rRNA gene was determined for at least one isolate from each LSU group. See Fig. 1 for GenBank/EMBL/DDBJ accession numbers for SSU rRNA gene sequences. The base pair differences are from sequence comparisons between type strain (T) and other isolates in each species in the D1/D2 region of the LSU rRNA gene (about $600 \mathrm{bp}$ ) and the SSU rRNA gene (about 1750 bp). C. ambrosiae isolates from this study were compared with its type strain, NRRL YB- $1316^{\mathrm{T}}$. 


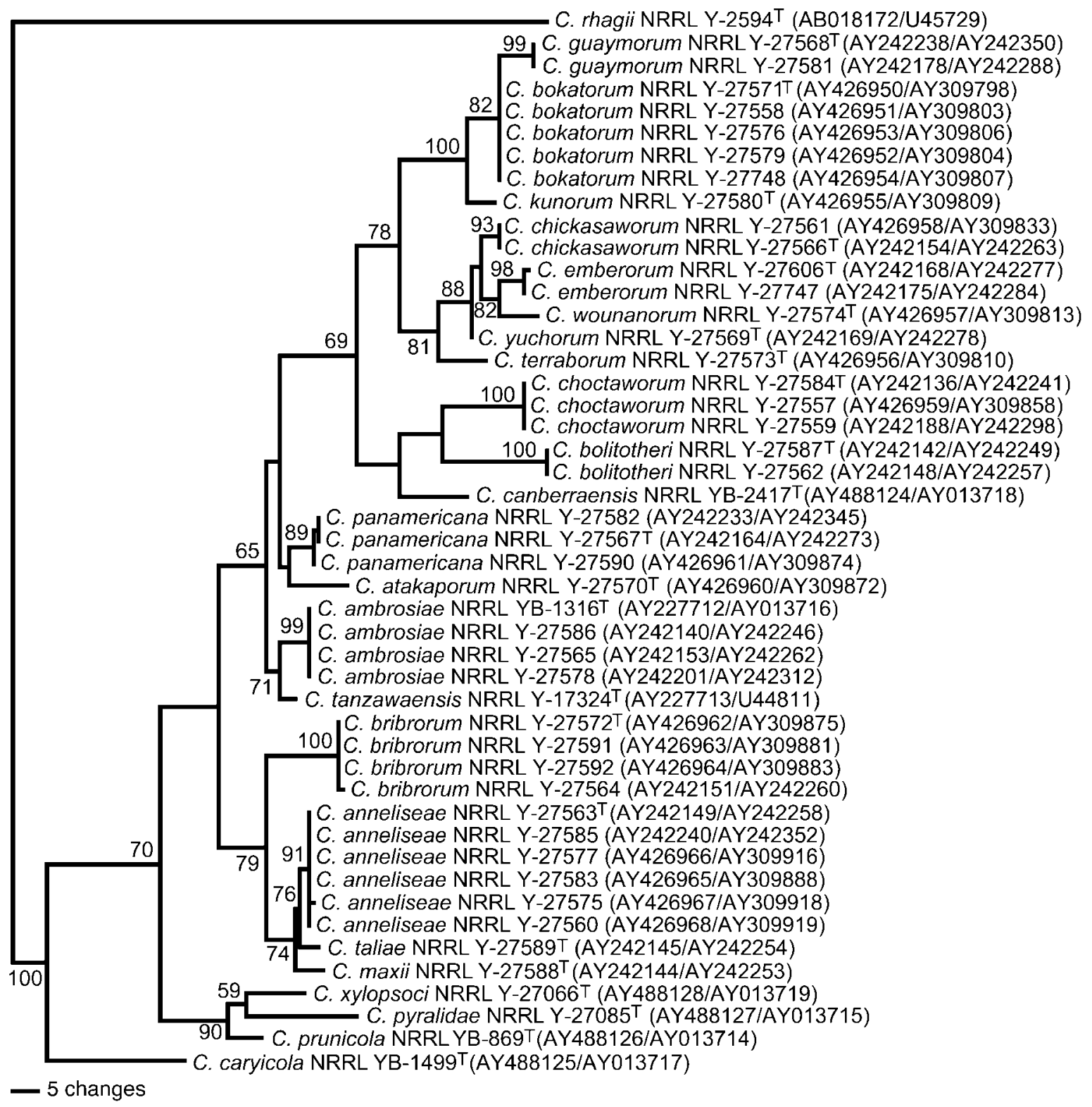

Fig. 1. Consensus of two most-parsimonious trees obtained from combined SSU and LSU rRNA gene sequence data. Candida rhagii was chosen as the outgroup taxon based on analyses including a broader range of taxa (not shown). GenBank/EMBL/DDBJ accession numbers after the names of yeast species are for SSU and LSU rRNA gene sequence, respectively. Tree length $=514$; consistency index $=0 \cdot 6381$; homoplasy index $=0 \cdot 3619$; retention index $=0 \cdot 8444$; rescaled consistency index $=0.5388$. Numbers on tree branches indicate the percentages of bootstrap samplings derived from 1000 samples that supported the internal branches by $50 \%$ or higher.

previously described taxa, C. xylopsoci, C. pyralidae, $C$. prunicola and C. caryicola were basal to the other yeasts in the CT clade. C. ambrosiae, C. tanzawaensis and C. canberraensis, however, were included among the beetle gut yeasts (Fig. 1). Within the CT clade, the beetle isolates were resolved into 17 subclades with sufficient divergence to warrant species-level recognition (Kurtzman \& Robnett, 1998; Kurtzman, 2000; Suh \& Blackwell, 2004) (Fig. 1).
As mentioned earlier, only one subclade (including Erot8, Niti14 and Tene7) had D1/D2 sequences identical to the previously described yeast C. ambrosiae, which we consider to be conspecific with these isolates. There were marked differences between $C$. ambrosiae and the other 16 subclades in the CT clade with 6 bp or more (usually more than $20 \mathrm{bp}$ ) difference between the subclades. The genetic variation among multiple isolates within subclades was lower (Table 1; Fig. 1). For example, yeasts designated Endo2 and 
Erot24 occurred in a common subclade and differed from each other by $3 \mathrm{bp}$ of D1/D2 sequence. Also, there were minor D1/D2 sequence differences between common subclade members Tene 28 and Tene 30 or Erot 20 and Tene 19 (Table 1). Within all 17 subclades of the CT clade, however, the sequence variation of D1/D2 among subclade members was always less than $3 \mathrm{bp}$, within the range of species-level variation recognized in studies of other ascomycete yeast species (Kurtzman \& Robnett, 1998; Table 1).

We observed minor morphological differences among the isolates on YM and cornmeal agars at 5-7 days incubation and in YM broth after 5 days incubation at $25^{\circ} \mathrm{C}$, but morphological variation that consistently distinguished the yeasts within clades was not evident. One morphological feature common to all isolates was the lack of ascospore production. Physiological characters (Table 2), however, were more variable and these traits were useful to separate the other species of the CT clade. Below, we characterize and describe 16 novel species of beetle gut yeasts and compare them to the previously described yeasts of the CT clade (Fig. 1 and Table 2).

\section{Latin diagnosis of Candida guaymorum Suh et Blackwell sp. nov.}

In medio liquido dextrosum et peptonum et extractum levidinis continente post 7 dies ad $25^{\circ} \mathrm{C}$ cellulae vegetativae globosae aut ellipsoideae $(1 \cdot 25-6 \cdot 25 \times 1 \cdot 25-7 \cdot 5 \mu \mathrm{m})$, singulae vel binae; pseudohyphae fiunt. Cultura in agaro extramalti et faecis continente post 7 dies ad $25^{\circ} \mathrm{C}$, albida, hebes, teres et margine ciliata. In agaro farina Zeae maydis confecto post 10 dies ad $25^{\circ} \mathrm{C}$, pseudohyphae fiunt, hyphae verae non fiunt. Ascosporae non fiunt. Glucosum, galactosum (lente), maltosum (infirme, variabilitre), methyl $\alpha$-D-glucosidum (infirme, variabilitre), sucrosum (infirme, variabilitre), trehalosum et cellobiosum (lente) fermentantur. Melibiosum, lactosum, melezitosum, raffinosum, inulinum, amylum solubile et D-xylosum non fermentantur. Assimilantur glucosum, galactosum, D-glucosaminum, D-xylosum, sucrosum, maltosum, trehalosum, methyl $\alpha$-D-glucosidum, cellobiosum, salicinum, arbutinum, melezitosum, glycerolum, ribitolum, D-glucitolum, D-mannitolum, gluconolactonum, 2-keto-D-gluconatum, D-gluconatum (lente, infirme), acidum succinicum, acidum citricum et ethanolum. Non assimilantur L-sorbosum, D-ribosum, L-arabinosum, D-arabinosum, Lrhamnosum, melibiosum, lactosum, raffinosum, inulinum, amylum solubile, erythritolum, xylitolum, L-arabinitolum, galactitolum, inositolum, D-glucuronatum, DL-acidum lacticum, methanolum, propane-1,2-diolum, butano-2,3-diolum, acidum quinicum, D-glucaratum et $\mathrm{D}$-galactonatum. Assimilantur ethylaminum, L-lysinum, cadaverinum et glucosaminum. Non assimilantur kali nitratum, sodii nitritum, creatinum, creatininum, imidazolum et D-tryptophanum. Amylum non formatur. Biotinum externum ad crescentiam necessarium est. Augmentum non fiunt in temperatura $40{ }^{\circ} \mathrm{C}$. Non crescit in medio $10 \mu \mathrm{g} \mathrm{ml}^{-1}$ cycloheximido addito. Typus: NRRL Y-27568 ${ }^{\mathrm{T}}\left(=\mathrm{CBS} 9823^{\mathrm{T}}\right)$, designat stirpem typicum. Isolata a ile coleopterorum (Mycotretus interstitialis;
Erotylidae), Barro Colorado Island, Panama, depositata in Collectione Culturarum (NRRL), Peoria, IL, USA.

\section{Description of Candida guaymorum Suh \& Blackwell sp. nov.}

Candida guaymorum (gu.ay.mo'rum. N.L. m. gen. guaymorum to commemorate the Guaymí, a group of indigenous people of Panama with detailed knowledge of the forest flora).

After 7 days growth in YM broth at $25^{\circ} \mathrm{C}$, cells are globose to ellipsoidal $(1 \cdot 25-6 \cdot 25 \times 1 \cdot 25-7 \cdot 5 \mu \mathrm{m})$, and occur singly, in pairs or in short chains (Fig. 2a). Pseudohyphae are present. After 7 days on $\mathrm{YM}$ agar at $25^{\circ} \mathrm{C}$, colonies are white to cream-coloured with pale-pinkish perimeter on some old colonies, smooth, shiny, flat and filamentous in margin. After 10 days Dalmau plate culture on corn meal agar at $25{ }^{\circ} \mathrm{C}$, pseudohyphae are present; septate hyphae are absent. Aerobic growth is white, shiny and smooth with filamentous margin. No ascospores produced after 6 weeks at $17^{\circ} \mathrm{C}$ from individual strains on YM agar or strains crossed in all combinations on half-strength cornmeal agar. See Table 2 for a summary of physiological and other characteristics.

The type strain is NRRL Y $-27568^{\mathrm{T}}\left(=\mathrm{CBS} 9823^{\mathrm{T}}\right)$.

\section{Latin diagnosis of Candida bokatorum Suh et Blackwell sp. nov.}

In medio liquido dextrosum et peptonum et extractum levidinis continente post 7 dies ad $25^{\circ} \mathrm{C}$ cellulae vegetativae globosae aut ellipsoideae $(2-6 \times 3-6 \mu \mathrm{m})$, singulae vel binae. Cultura in agaro extramalti et faecis continente post 7 dies ad $25^{\circ} \mathrm{C}$, albida, hebes, butyrosa, margine ciliata. In agaro farina Zeae maydis confecto post 10 dies ad $25^{\circ} \mathrm{C}$, pseudohyphae fiunt; hyphae verae fiunt. Ascosporae non fiunt. Glucosum, maltosum (infirme, variabilitre), sucrosum (infirme, variabilitre), trehalosum et cellobiosum fermentantur. Galactosum, methyl $\alpha$-D-glucosidum, melibiosum, lactosum, melezitosum, raffinosum, inulinum, amylum solubile et D-xylosum non fermentantur. Assimilantur glucosum, galactosum, D-glucosaminum (variabilitre), D-xylosum, D-arabinosum, sucrosum, maltosum, trehalosum, methyl $\alpha$-D-glucosidum, cellobiosum, salicinum, arbutinum, melezitosum, glycerolum, ribitolum, D-glucitolum, Dmannitolum, gluconolactonum, 2-keto-D-gluconatum, Dgluconatum (lente, infirme), acidum succinicum, acidum citricum, ethanolum et propane-1,2-diolum (infirme, variabilitre). Non assimilantur L-sorbosum, D-ribosum, L-arabinosum, L-rhamnosum, melibiosum, lactosum, raffinosum, inulinum, amylum solubile, erythritolum, xylitolum, L-arabinitolum, galactitolum, inositolum, D-glucuronatum, DL-acidum lacticum, methanolum, butano-2,3-diolum, acidum quinicum, D-glucaratum et D-galactonatum. Assimilantur ethylaminum, L-lysinum, cadaverinum et glucosaminum (infirme, variabilitre). Non assimilantur kali nitratum, sodii nitritum, creatinum, creatininum, 
Table 2. Physiological characteristics of novel Candida species and C. ambrosia from this study

Taxa: 1, C. guaymorum; 2, C. bokatorum; 3, C. kunorum; 4, C. terraborum; 5, C. emberorum; 6, C. wounanorum; 7, C. yuchorum; 8, C. chickasaworum; 9, C. choctaworum; 10, C. bolitotheri; 11, C. atakaporum; 12, C. panamericana; 13. C. bribrorum; 14, C. maxii; 15, C. anneliseae; 16, C. taliae; 17, C. ambrosiae from this study. The following characteristics are invariable in all species compared. Fermentation of melibiose $(-)$, raffinose $(-)$, starch $(-)$, D-xylose $(-)$, D-glucose $(+)$; assimilation of D-rhamnose $(-)$, trehalose $(+)$, cellobiose $(+)$, melibiose $(-)$, lactose $(-)$, raffinose $(-)$, inulin $(-)$, D-glucitol $(+)$, D-mannitol $(+)$, galactitol $(-)$, myo-inositol $(-)$, D-glucuronate $(-)$, methanol $(-)$, butane-2,3-diol $(-)$, quinic acid $(-)$, D-glucarate $(-)$, D-galactonate $(-)$, nitrate $(-)$, nitrite $(-)$, ethylamine $(+)$, D-lysine $(+)$, cadaverine $(+)$, creatine $(-)$, creatinine $(-)$, imidazole $(-)$; vitamin requirement, growth without pantothenate $(+)$, niacin $(+)$, $p$-aminobenzoic acid $(+)$; growth at $25^{\circ} \mathrm{C}(+)$, at $30^{\circ} \mathrm{C}(+)$, at $40{ }^{\circ} \mathrm{C}(-)$; growth on $1 \%$ acetic acid (-); additional tests, starch formation (-), urea hydrolysis (-), Diazonium Blue B reaction (-). Abbreviations: +, positive reaction; - , negative reaction; d, delayed positive reaction; $\mathrm{W}$, weak positive reaction; $\mathrm{V}$, variable reaction; w/o, without.

\begin{tabular}{|c|c|c|c|c|c|c|c|c|c|c|c|c|c|c|c|c|c|}
\hline Characteristic & 1 & 2 & 3 & 4 & 5 & 6 & 7 & 8 & 9 & 10 & 11 & 12 & 13 & 14 & 15 & 16 & 17 \\
\hline \multicolumn{18}{|c|}{ Fermentation of carbon compounds } \\
\hline D-Glucose & + & $+/ \mathrm{d}$ & + & $\mathrm{d}$ & + & $\mathrm{d}$ & + & + & $+/ \mathrm{d}$ & + & + & + & + & $\mathrm{d}$ & $+/ \mathrm{d} / \mathrm{w}$ & + & + \\
\hline Maltose & $\mathrm{w} /-$ & $\mathrm{w} /-$ & $\mathrm{W}$ & $\mathrm{d}$ & - & - & - & - & - & - & - & - & $\mathrm{w} /-$ & - & - & - & $\mathrm{d} / \mathrm{w}$ \\
\hline Methyl $\alpha$-D-glucoside & $\mathrm{w} /-$ & - & - & - & - & - & - & - & - & - & - & - & - & - & - & - & $\mathrm{V}$ \\
\hline Sucrose & $\mathrm{w} /-$ & $\mathrm{w} /-$ & - & $\mathrm{d}$ & - & - & - & - & - & - & - & - & - & - & - & - & $\mathrm{d} / \mathrm{w}$ \\
\hline Lactose & - & - & $\mathrm{W}$ & - & - & - & - & - & - & - & - & - & - & - & - & - & - \\
\hline Cellobiose & $\mathrm{d}$ & $+/ \mathrm{d}$ & - & - & $\mathrm{d} / \mathrm{w}$ & - & $\mathrm{d}$ & - & - & - & - & $\mathrm{d} / \mathrm{w}$ & - & $\mathrm{w}$ & - & $\mathrm{d}$ & $\mathrm{V}$ \\
\hline Melezitose & - & - & - & - & - & - & - & - & - & - & - & - & - & - & - & - & $\mathrm{w} /-$ \\
\hline Inulin & - & - & - & - & - & - & - & - & - & - & - & - & - & - & - & - & $\mathrm{w} /-$ \\
\hline \multicolumn{18}{|c|}{ Assimilation of carbon compounds } \\
\hline D-Xylose & + & + & $\mathrm{d}$ & $\mathrm{w}$ & + & + & + & $+/ \mathrm{d}$ & $+/ \mathrm{d}$ & $+/ \mathrm{d} / \mathrm{w}$ & + & + & + & - & $+/ \mathrm{d} / \mathrm{w}$ & $\mathrm{d}$ & + \\
\hline L-Arabinose & - & - & - & - & - & - & - & - & $\mathrm{w} /-$ & - & - & - & $\mathrm{V}$ & - & - & - & $+/ \mathrm{d} / \mathrm{w}$ \\
\hline D-Arabinose & - & $+/ \mathrm{d} / \mathrm{w}$ & w & - & - & - & - & - & $+/ \mathrm{d} / \mathrm{w}$ & - & $\mathrm{w}$ & - & $\mathrm{V}$ & $\mathrm{w}$ & $+/ \mathrm{d} / \mathrm{w}$ & + & - \\
\hline Sucrose & + & + & + & + & + & + & + & + & - & - & + & + & + & + & + & + & + \\
\hline Maltose & + & + & + & + & + & + & + & + & - & - & + & + & + & + & + & + & + \\
\hline Methyl $\alpha$-D-glucoside & + & + & + & + & + & + & + & + & - & - & + & + & + & + & + & + & + \\
\hline Salicin & + & + & $\mathrm{d}$ & + & + & + & + & + & + & + & + & + & + & + & + & + & + \\
\hline Arbutin & + & + & + & + & + & + & + & + & + & + & + & $+/ \mathrm{d}$ & + & + & + & + & + \\
\hline Melezitose & + & + & + & + & $\mathrm{d} / \mathrm{w}$ & $\mathrm{w}$ & - & $\mathrm{V}$ & - & - & + & + & + & + & + & + & + \\
\hline Soluble starch & - & - & - & - & - & - & - & - & - & - & $\mathrm{w}$ & - & - & - & - & - & - \\
\hline Glycerol & + & $+/ \mathrm{d} / \mathrm{w}$ & + & + & + & + & + & + & $+/ \mathrm{d}$ & + & + & + & + & $\mathrm{d}$ & $+/ \mathrm{d} / \mathrm{w}$ & + & + \\
\hline DL-Lactate & - & - & - & - & - & - & - & - & - & - & $\mathrm{d}$ & - & - & - & - & - & - \\
\hline Succinate & + & $+/ \mathrm{d}$ & + & + & + & $\mathrm{d}$ & + & + & $+/ \mathrm{w}$ & $+/ \mathrm{d} / \mathrm{w}$ & $\mathrm{d}$ & + & $+/ \mathrm{d}$ & + & $+/ \mathrm{d}$ & + & + \\
\hline Citrate & + & + & $\mathrm{d}$ & + & $+/ \mathrm{d}$ & + & + & $+/ \mathrm{d} / \mathrm{w}$ & $+/ \mathrm{d}$ & + & $\mathrm{d}$ & + & + & + & $+/ \mathrm{d}$ & + & + \\
\hline Ethanol & $+/ \mathrm{w}$ & + & + & $\mathrm{d}$ & + & + & - & $+/ \mathrm{d} / \mathrm{w}$ & $+/ \mathrm{d}$ & $+/ \mathrm{d}$ & + & - & + & + & $+/ \mathrm{d} / \mathrm{w}$ & + & + \\
\hline Propane-1,2-diol & - & $\mathrm{w} /-$ & $\mathrm{w}$ & $\mathrm{W}$ & - & - & - & $\mathrm{w} /-$ & $\mathrm{w} /-$ & - & $\mathrm{w}$ & - & - & - & $\mathrm{w} /-$ & - & - \\
\hline \multicolumn{18}{|c|}{ Assimilation of nitrogen compounds } \\
\hline D-Glucosamine & $+/ \mathrm{w}$ & $\mathrm{w} /-$ & $\mathrm{w}$ & $\mathrm{W}$ & $+/ \mathrm{w}$ & - & + & $\mathrm{V}$ & $\mathrm{V}$ & $+/ \mathrm{w}$ & $\mathrm{w}$ & $\mathrm{V}$ & $\mathrm{V}$ & $\mathrm{w}$ & $\mathrm{V}$ & $\mathrm{w}$ & $\mathrm{V}$ \\
\hline D-Tryptophan & - & - & - & - & $\mathrm{w}$ & - & $\mathrm{d}$ & - & - & - & $\mathrm{d}$ & - & - & - & - & - & - \\
\hline
\end{tabular}


Table 2. cont.

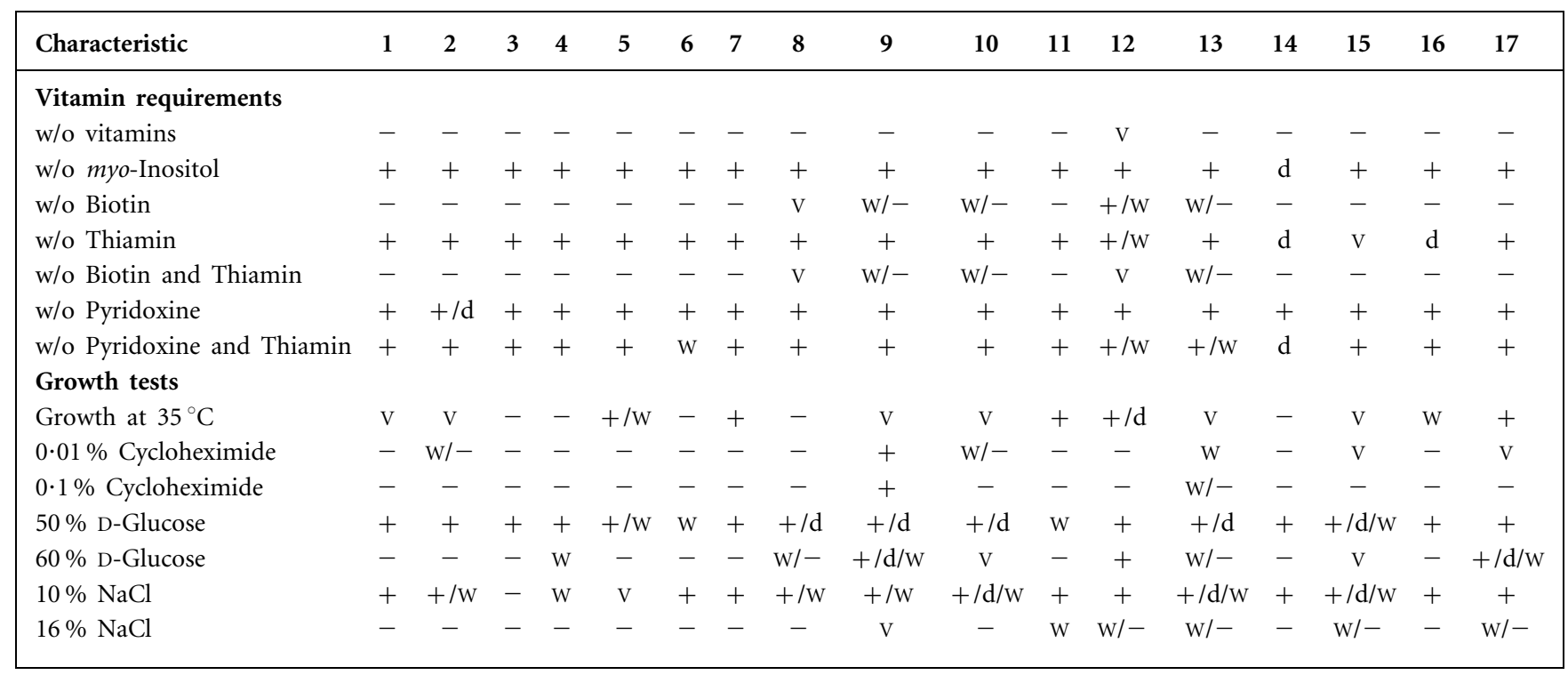

imidazolum et D-tryptophanum. Amylum non formatur. Biotinum externum ad crescentiam necessarium est. Augmentum non fiunt in temperatura $40^{\circ} \mathrm{C}$. Variabilitre in medio $10 \mu \mathrm{g} \mathrm{ml}^{-1}$ cycloheximido addito, non crescit in medio $100 \mu \mathrm{g} \mathrm{ml}^{-1}$. Typus: NRRL Y-27571 ${ }^{\mathrm{T}}\left(=\mathrm{CBS} 9824^{\mathrm{T}}\right)$, designat stirpem typicum. Isolata a ile coleopterorum (Pselaphacus signatus; Erotylidae), Barro Colorado Island, Panama, depositata in Collectione Culturarum (NRRL), Peoria, IL, USA.

\section{Description of Candida bokatorum Suh \& Blackwell sp. nov.}

Candida bokatorum (bo.ka.to' rum. N.L. m. gen. bokatorum to commemorate the Bókatá, a group of indigenous people of Panama, linguistically related to the Guaymí).

After 7 days growth in YM broth at $25^{\circ} \mathrm{C}$, cells are globose to ellipsoidal $(2-6 \times 3-6 \mu \mathrm{m})$, mostly subglobose, and occur singly, in pairs or in short chains (Fig. 2b). Pseudohyphae may be present. After 7 days on YM agar at $25^{\circ} \mathrm{C}$, colonies are white to cream in colour, butyrous and smooth. After 10 days Dalmau plate culture on corn meal agar at $25^{\circ} \mathrm{C}$, pseudohyphae are present. Septate hyphae may be present. Aerobic growth is white and smooth. No ascospores produced after 6 weeks at $17^{\circ} \mathrm{C}$ from individual strains on YM agar or strains crossed in all combinations on halfstrength cornmeal agar. See Table 2 for a summary of physiological and other characteristics.

The type strain is NRRL Y $-27571^{\mathrm{T}}\left(=\mathrm{CBS} 9824^{\mathrm{T}}\right)$.

\section{Latin diagnosis of Candida kunorum Suh et Blackwell sp. nov.}

In medio liquido dextrosum et peptonum et extractum levidinis continente post 7 dies ad $25^{\circ} \mathrm{C}$ cellulae vegetativae subglobosae aut fusiformes $(2-5 \times 3-6 \mu \mathrm{m})$, singulae vel binae. Cultura in agaro extramalti et faecis continente post 7 dies ad $25^{\circ} \mathrm{C}$, albida, hebes, butyrosa, margine ciliata. In agaro farina Zeae maydis confecto post 10 dies ad $25^{\circ} \mathrm{C}$, pseudohyphae non fiunt; hyphae verae non fiunt. Ascosporae non fiunt. Glucosum, galactosum (infirme), maltosum (infirme), trehalosum et lactosum (infirme) fermentantur. Sucrosum, methyl $\alpha$-D-glucosidum, melibiosum, cellobiosum, melezitosum, raffinosum, inulinum, amylum solubile et D-xylosum non fermentantur. Assimilantur glucosum, galactosum, D-glucosaminum (lente), D-ribosum (infirme), D-xylosum (lente), D-arabinosum (infirme), sucrosum, maltosum, trehalosum, methyl $\alpha$-D-glucosidum, cellobiosum, salicinum (lente), arbutinum, melezitosum, glycerolum, ribitolum, xylitolum (infirme), L-arabinitolum (infirme), D-glucitolum, D-mannitolum, gluconolactonum, 2-keto-Dgluconatum, D-gluconatum, acidum succinicum, acidum citricum (lente), ethanolum et propane-1,2-diolum (infirme). Non assimilantur L-sorbosum, L-arabinosum, L-rhamnosum, melibiosum, lactosum, raffinosum, inulinum, amylum solubile, erythritolum, galactitolum, inositolum, D-glucuronatum, DL-acidum lacticum, methanolum, butano-2,3-diolum, acidum quinicum et D-glucaratum. Assimilantur ethylaminum, L-lysinum, cadaverinum et glucosaminum (infirme). Non assimilantur kali nitratum, sodii nitritum, creatinum, creatininum, imidazolum et D-tryptophanum. Amylum non formatur. Biotinum externum ad crescentiam necessarium est. Augmentum non funt in temperatura $35^{\circ} \mathrm{C}$. Typus: NRRL Y-27580 $\left(=\mathrm{CBS} 9825^{\mathrm{T}}\right)$, designat stirpem typicum. Isolata a ile coleopterorum (Teichostethus testaceous; Nitidulidae), Barro Colorado Island, Panama, depositata in Collectione Culturarum (NRRL), Peoria, IL, USA.

\section{Description of Candida kunorum Suh \& Blackwell sp. nov.}

Candida kunorum (ku.no'rum. N.L. m. gen. kunorum to commemorate the Kuna, a group of indigenous people of 


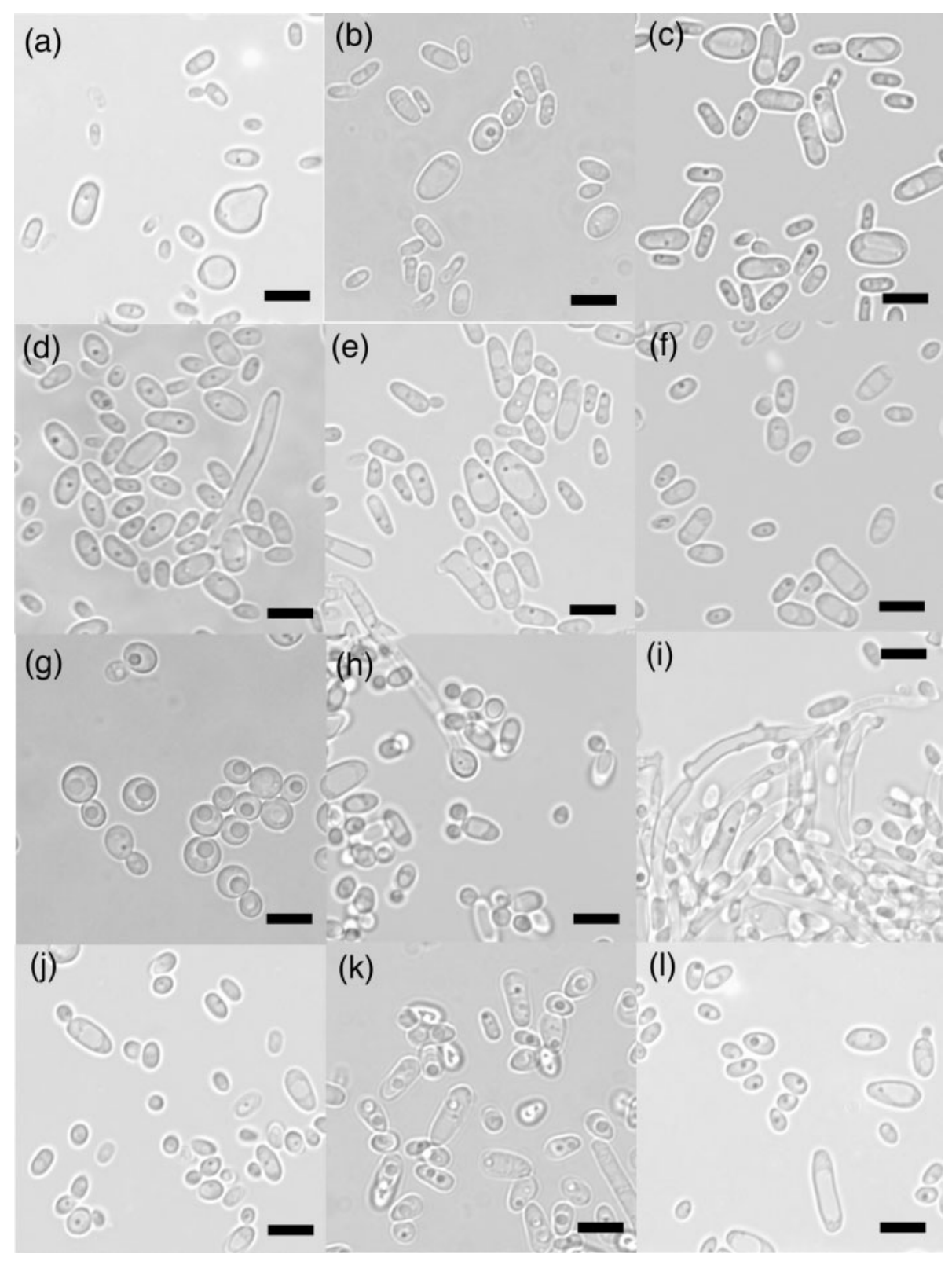

Fig. 2. Budding yeast cells, pseudohyphae and septate hyphae of the novel species. (a) C. guaymorum NRRL Y-27568 ${ }^{\top}$; (b) C. bokatorum NRRL Y-27571 ${ }^{\top}$; (c) C. kunorum NRRL Y-27580 ${ }^{\top}$; (d) C. terraborum NRRL Y-27573 $3^{\top}$; (e) C. emberorum NRRL Y-27606 ${ }^{\top}$; (f) C. wounanorum NRRL Y-27574 ${ }^{\top}$; (g) C. yuchorum NRRL Y-27569 ${ }^{\top}$; (h) C. chickasaworum NRRL Y$27566^{\top}$; (i) C. choctaworum NRRL Y-27584 ${ }^{\top}$; (j) Candida bolitotheri NRRL Y-27587 ${ }^{\top}$; (k) C. atakaporum NRRL Y-27570'; (I) C. panamericana NRRL Y-27567 ${ }^{\top}$. (a-f, h-l) Seven days, half-strength cornmeal agar, $25^{\circ} \mathrm{C}$; (g) 5 days, $\mathrm{YM}$ broth, $25^{\circ} \mathrm{C}$. Bars, $5 \mu \mathrm{m}$.

Panama with a high degree of literacy and a desire for autonomy).

After 7 days growth in YM broth at $25^{\circ} \mathrm{C}$, cells are subglobose to fusiform $(2-5 \times 3-6 \mu \mathrm{m})$, mostly subglobose, and occur singly, in pairs or in short chains (Fig. 2c). After 7 days on $\mathrm{YM}$ agar at $25^{\circ} \mathrm{C}$, colonies are white, membranous and butyrous with smooth margin. After 10 days Dalmau plate culture on corn meal agar at $25^{\circ} \mathrm{C}$, pseudohyphae and septate hyphae are absent. Aerobic growth is white and smooth. No ascospores produced after 6 weeks at $17^{\circ} \mathrm{C}$ from the single strain on YM agar or half-strength cornmeal agar. See Table 2 for a summary of physiological and other characteristics.

The type strain is NRRL Y-27580 $\left(=\right.$ CBS $\left.9825^{\mathrm{T}}\right)$. 


\section{Latin diagnosis of Candida terraborum Suh et Blackwell sp. nov.}

In medio liquido dextrosum et peptonum et extractum levidinis continente post 7 dies ad $25^{\circ} \mathrm{C}$ cellulae vegetativae globosae aut ellipsoideae $(4-6 \times 5-7 \mu \mathrm{m})$, singulae vel binae. Cultura in agaro extramalti et faecis continente post 7 dies ad $25^{\circ} \mathrm{C}$, albida, hebes, butyrosa, margine ciliata. In agaro farina Zeae maydis confecto post 10 dies ad $25^{\circ} \mathrm{C}$, pseudohyphae fiunt; hyphae verae non fiunt. Ascosporae non fiunt. Glucosum (lente), galactosum (infirme), maltosum (lente), sucrosum (lente) et trehalosum (lente) fermentantur. Methyl $\alpha$-D-glucosidum, melibiosum, lactosum, cellobiosum, melezitosum, raffinosum, inulinum, amylum solubile et D-xylosum non fermentantur. Assimilantur glucosum, galactosum, D-glucosaminum (infirme), D-xylosum (infirme), sucrosum, maltosum, trehalosum, methyl $\alpha$-D-glucosidum, cellobiosum, salicinum, arbutinum, melezitosum, glycerolum, ribitolum, D-glucitolum, D-mannitolum, gluconolactonum (infirme), 2-keto-D-gluconatum, D-gluconatum (infirme), acidum succinicum, acidum citricum, ethanolum (lente) et propane-1,2-diolum (infirme). Non assimilantur D-sorbosum, D-ribosum, L-arabinosum, D-arabinosum, D-rhamnosum, melibiosum, lactosum, raffinosum, inulinum, amylum solubile, erythritolum, xylitolum, D-arabinitolum, galactitolum, inositolum, D-glucuronatum, DL-acidum lacticum, methanolum, butano-2,3-diolum, acidum quinicum, D-glucaratum et D-galactonatum. Assimilantur ethylaminum, D-lysinum, cadaverinum et glucosaminum (infirme). Non assimilantur kali nitratum, sodii nitritum, creatinum, creatininum, imidazolum et D-tryptophanum. Amylum non formatur. Biotinum externum ad crescentiam necessarium est. $30^{\circ} \mathrm{C}$ crescit neque $35^{\circ} \mathrm{C}$. Non crescit in medio $10 \mu \mathrm{g} \mathrm{ml}^{-1}$ cycloheximido addito. Typus: NRRL Y-27573 ${ }^{\mathrm{T}}$ (=CBS $9826^{\mathrm{T}}$ ), designat stirpem typicum. Isolata a ile coleopterorum (Iphiclus sedecimmaculatus; Erotylidae), Barro Colorado Island, Panama, depositata in Collectione Culturarum (NRRL), Peoria, IL, USA.

\section{Description of Candida terraborum Suh \& Blackwell sp. nov.}

Candida terraborum (ter.ra.bo' rum. N.L. m. gen. terraborum to commemorate the Térraba, a group of indigenous people of Panama, survivors of epidemics that once decimated their numbers).

After 7 days growth in YM broth at $25^{\circ} \mathrm{C}$, cells are globose to ellipsoidal $(4-6 \times 5-7 \mu \mathrm{m})$, mostly subglobose, and occur singly, in pairs or in short chains (Fig. 2d). Big and elongated cells are also observed. After 7 days on YM agar at $25^{\circ} \mathrm{C}$, colonies are off-white, butyrous and smooth. After 10 days Dalmau plate culture on corn meal agar at $25^{\circ} \mathrm{C}$, pseudohyphae are present; septate hyphae are absent. Aerobic growth is white with fuzzy margin. No ascospores produced after 6 weeks at $17^{\circ} \mathrm{C}$ from the single strain on YM agar or half-strength cornmeal agar. See Table 2 for a summary of physiological and other characteristics.
The type strain is NRRL Y $-27573^{\mathrm{T}}\left(=\mathrm{CBS} 9826^{\mathrm{T}}\right)$.

\section{Latin diagnosis of Candida emberorum Suh et Blackwell sp. nov.}

In medio liquido dextrosum et peptonum et extractum levidinis continente post 7 dies ad $25{ }^{\circ} \mathrm{C}$ cellulae vegetativae globosae aut ellipsoideae $(1 \cdot 25-5 \times 2 \cdot 5-6 \cdot 25 \mu \mathrm{m})$, singulae vel binae. Cultura in agaro extramalti et faecis continente post 7 dies ad $25^{\circ} \mathrm{C}$, albida, hebes, butyrosa, margine ciliata. In agaro farina Zeae maydis confecto post 10 dies ad $25^{\circ} \mathrm{C}$, pseudohyphae fiunt; hyphae verae non fiunt. Ascosporae non funt. Glucosum, galactosum, trehalosum et cellobiosum (lente, infirme) fermentantur. Maltosum, methyl $\alpha$-Dglucosidum, sucrosum, melibiosum, lactosum, melezitosum, raffinosum, inulinum, amylum solubile et D-xylosum non fermentantur. Assimilantur glucosum, galactosum, Dglucosaminum (lente, infirme), D-xylosum, sucrosum, maltosum, trehalosum, methyl $\alpha$-D-glucosidum, cellobiosum, salicinum, arbutinum, melezitosum (lente, infirme), glycerolum, ribitolum, D-glucitolum, D-mannitolum, gluconolactonum, 2-keto-D-gluconatum, D-gluconatum (lente, infirme), acidum succinicum, acidum citricum et ethanolum. Non assimilantur D-sorbosum, D-ribosum, L-arabinosum, Darabinosum, D-rhamnosum, melibiosum, lactosum, raffinosum, inulinum, amylum solubile, erythritolum, xylitolum, D-arabinitolum, galactitolum, inositolum, D-glucuronatum, DL-acidum lacticum, methanolum, propane-1,2-diolum, butano-2,3-diolum, acidum quinicum, D-glucaratum et D-galactonatum. Assimilantur ethylaminum, D-lysinum, cadaverinum, glucosaminum et D-tryptophanum (infirme). Non assimilantur kali nitratum, sodii nitritum, creatinum, creatininum et imidazolum. Amylum non formatur. Biotinum externum ad crescentiam necessarium est. Augmentum non funt in temperatura $40{ }^{\circ} \mathrm{C}$. Non crescit in medio $10 \mu \mathrm{g} \mathrm{ml} \mathrm{m}^{-1}$ cycloheximido addito. Typus: NRRL Y-27606 ${ }^{\mathrm{T}}$ (=CBS $9827^{\mathrm{T}}$ ), designat stirpem typicum. Isolata a ile coleopterorum (Triplax alvarengai; Erotylidae), Barro Colorado Island, Panama, depositata in Collectione Culturarum (NRRL), Peoria, IL, USA.

\section{Description of Candida emberorum Suh \& Blackwell sp. nov.}

Candida emberorum (em.be.ro'rum. N.L. m. gen. emberozrum to commemorate the Emberá, a group of indigenous people of Panama, knowledgeable in botanical lore).

After 7 days growth in YM broth at $25^{\circ} \mathrm{C}$, cells are globose to ellipsoidal $(1 \cdot 25-5 \times 2 \cdot 5-6 \cdot 25 \mu \mathrm{m})$, mostly globose or subglobose, and occur singly, in pairs or in short chains (Fig. 2e). Pseudohyphae may be present. After 7 days on YM agar at $25^{\circ} \mathrm{C}$, colonies are white to cream-coloured with pale-pinkish perimeter, smooth and butyrous. After 10 days Dalmau plate culture on corn meal agar at $25^{\circ} \mathrm{C}$, pseudohyphae are present; septate hyphae are absent. Aerobic growth is white, dull and smooth with filamentous margin. No ascospores produced after 6 weeks at $17^{\circ} \mathrm{C}$ from individual strains on YM agar or strains crossed in all 
combinations on half-strength cornmeal agar. See Table 2 for a summary of physiological and other characteristics.

The type strain is NRRL Y-27606 $\left(=\right.$ CBS $\left.9827^{\mathrm{T}}\right)$.

\section{Latin diagnosis of Candida wounanorum Suh et Blackwell sp. nov.}

In medio liquido dextrosum et peptonum et extractum levidinis continente post 7 dies ad $25^{\circ} \mathrm{C}$ cellulae vegetativae globosae aut ovoidae $(2-4 \times 3-6 \mu \mathrm{m})$, plerumque subglobosae, singulae vel binae. Cultura in agaro extramalti et faecis continente post 7 dies ad $25^{\circ} \mathrm{C}$, albida, butyrosa. In agaro farina Zeae maydis confecto post 10 dies ad $25^{\circ} \mathrm{C}$, pseudohyphae non fiunt; hyphae verae non fiunt. Ascosporae non fiunt. Glucosum (lente), galactosum (infirme) et trehalosum (lente) fermentantur. Maltosum, methyl $\alpha$-Dglucosidum, sucrosum, melibiosum, lactosum, cellobiosum, melezitosum, raffinosum, inulinum, amylum solubile et D-xylosum non fermentantur. Assimilantur glucosum, galactosum, D-glucosaminum (lente), D-xylosum, sucrosum, maltosum, trehalosum, methyl $\alpha$-D-glucosidum, cellobiosum, salicinum, arbutinum, melezitosum (infirme), glycerolum, ribitolum, D-glucitolum, D-mannitolum, gluconolactonum, 2-keto-D-gluconatum, acidum succinicum (lente), acidum citricum et ethanolum. Non assimilantur D-sorbosum, D-ribosum, L-arabinosum, D-arabinosum, D-rhamnosum, melibiosum, lactosum, raffinosum, inulinum, amylum solubile, erythritolum, xylitolum, D-arabinitolum, galactitolum, inositolum, D-gluconatum, D-glucuronatum, DL-acidum lacticum, methanolum, propane-1,2-diolum, butano-2,3diolum, acidum quinicum, D-glucaratum et D-galactonatum. Assimilantur ethylaminum, D-lysinum et cadaverinum. Non assimilantur kali nitratum, sodii nitritum, creatinum, creatininum, glucosaminum, imidazolum et D-tryptophanum. Amylum non formatur. Biotinum externum ad crescentiam necessarium est. In temperatura $30^{\circ} \mathrm{C}$ crescit neque $35^{\circ} \mathrm{C}$. Non crescit in medio $10 \mu \mathrm{g} \mathrm{ml}^{-1}$ cycloheximido addito. Typus: NRRL Y-27574 ${ }^{\mathrm{T}}\left(=\mathrm{CBS} 9828^{\mathrm{T}}\right)$, designat stirpem typicum. Isolata a ile coleopterorum (Mycotretus dorsonotatus; Erotylidae), Barro Colorado Island, Panama, depositata in Collectione Culturarum (NRRL), Peoria, IL, USA.

\section{Description of Candida wounanorum Suh \& Blackwell sp. nov.}

Candida wounanorum (wou.na.no'rum. N.L. m. gen. wounanorum to commemorate the Wounan, a group of indigenous people of Panama known for their artistry in using plant materials; they inhabited the same region as the Emberá).

After 7 days growth in $\mathrm{YM}$ broth at $25^{\circ} \mathrm{C}$, cells are globose to oval $(2-4 \times 3-6 \mu \mathrm{m})$, mostly subglobose, and occur singly, in pairs or in short chains (Fig. 2f). After 7 days on YM agar at $25^{\circ} \mathrm{C}$, colonies are off-white with fuzzy white spots, butyrous and smooth. After 10 days Dalmau plate culture on corn meal agar at $25^{\circ} \mathrm{C}$, pseudohyphae and septate hyphae are absent. Aerobic growth is white, shiny, smooth and filamentous in margin. No ascospores produced after 6 weeks at $17^{\circ} \mathrm{C}$ from the single strain on YM agar or half-strength cornmeal agar. See Table 2 for a summary of physiological and other characteristics.

The type strain is NRRL Y $-27574^{\mathrm{T}}\left(=\mathrm{CBS} 9828^{\mathrm{T}}\right)$.

\section{Latin diagnosis of Candida yuchorum Suh et Blackwell sp. nov.}

In medio liquido dextrosum et peptonum et extractum levidinis continente post 7 dies ad $25^{\circ} \mathrm{C}$ cellulae vegetativae globosae aut ellipsoideae $(2 \cdot 5-7 \times 2 \cdot 5-7 \mu \mathrm{m})$, plerumque globosae, singulae vel binae. Cultura in agaro extramalti et faecis continente post 7 dies ad $25^{\circ} \mathrm{C}$, albida, teres, margine ciliata. In agaro farina Zeae maydis confecto post 10 dies ad $25^{\circ} \mathrm{C}$, pseudohyphae et hyphae verae fiunt. Ascosporae non fiunt. Glucosum, galactosum (lente), trehalosum et cellobiosum (lente) fermentantur. Maltosum, methyl $\alpha$-D-glucosidum, sucrosum, melibiosum, lactosum, melezitosum, raffinosum, inulinum, amylum solubile et D-xylosum non fermentantur. Assimilantur glucosum, galactosum, D-xylosum, sucrosum, maltosum, trehalosum, methyl $\alpha$-D-glucosidum, cellobiosum, salicinum, arbutinum, glycerolum, ribitolum, D-glucitolum, D-mannitolum, gluconolactonum, 2-keto-D-gluconatum, Dgluconatum (lente), acidum succinicum et acidum citricum. Non assimilantur D-sorbosum, D-glucosaminum, D-ribosum, L-arabinosum, D-arabinosum, D-rhamnosum, melibiosum, lactosum, raffinosum, melezitosum, inulinum, amylum solubile, erythritolum, xylitolum, D-arabinitolum, galactitolum, inositolum, D-glucuronatum, DL-acidum lacticum, methanolum, ethanolum, propane-1,2-diolum, butano-2,3diolum, acidum quinicum, D-glucaratum et D-galactonatum. Assimilantur ethylaminum, D-lysinum, cadaverinum, glucosaminum et D-tryptophanum (lente). Non assimilantur kali nitratum, sodii nitritum, creatinum, creatininum et imidazolum. Amylum non formatur. Biotinum externum ad crescentiam necessarium est. Augmentum non fiunt in temperatura $40{ }^{\circ} \mathrm{C}$. Non crescit in medio $10 \mu \mathrm{g} \mathrm{ml} \mathrm{m}^{-1}$ cycloheximido addito. Typus: NRRL Y $-27569^{\mathrm{T}}$ (=CBS $9829^{\mathrm{T}}$ ), designat stirpem typicum. Isolata a ile coleopterorum (Tritoma atriventris; Erotylidae), Athens, GA, USA, depositata in Collectione Culturarum (NRRL), Peoria, IL, USA.

\section{Description of Candida yuchorum Suh \& Blackwell sp. nov.}

Candida yuchorum (yu.cho' rum. N.L. m. gen. yuchorum to commemorate the Yuchi, native Americans of the southeastern USA; their public worship was tied to the corn harvest when food was shared).

After 7 days growth in YM broth at $25^{\circ} \mathrm{C}$, cells are globose to ellipsoidal $(2 \cdot 5-7 \times 2 \cdot 5-7 \mu \mathrm{m})$, mostly globose or subglobose, and occur singly, in pairs or in short chains (Fig. 2g). Pseudohyphae and septate hyphae may be present. After 7 days on YM agar at $25^{\circ} \mathrm{C}$, colonies are creamcoloured, smooth and shiny with filamentous margin. After 10 days Dalmau plate culture on corn meal agar at 
$25^{\circ} \mathrm{C}$, pseudohyphae and septate hyphae may be present. Aerobic growth is white and dull. No ascospores produced after 6 weeks at $17^{\circ} \mathrm{C}$ from individual strains on YM agar or strains crossed in all combinations on half-strength cornmeal agar. See Table 2 for a summary of physiological and other characteristics.

The type strain is NRRL Y $-27569^{\mathrm{T}}\left(=\mathrm{CBS} 9829^{\mathrm{T}}\right)$.

\section{Latin diagnosis of Candida chickasaworum Suh \& Blackwell sp. nov.}

In medio liquido dextrosum et peptonum et extractum levidinis continente post 7 dies ad $25^{\circ} \mathrm{C}$ cellulae vegetativae globosae aut fusiformes $(2-6 \times 2-8 \mu \mathrm{m})$, singulae vel binae. Cultura in agaro extramalti et faecis continente post 7 dies ad $25^{\circ} \mathrm{C}$, albida, butyrosa, margine ciliata. In agaro farina Zeae maydis confecto post 10 dies ad $25^{\circ} \mathrm{C}$, pseudohyphae et hyphae verae fiunt. Ascosporae non fiunt. Glucosum, galactosum et trehalosum fermentantur. Maltosum, methyl $\alpha$-D-glucosidum, sucrosum, melibiosum, lactosum, cellobiosum, melezitosum, raffinosum, inulinum, amylum solubile et D-xylosum non fermentantur. Assimilantur glucosum, galactosum, D-glucosaminum (lente, infirme), D-xylosum, sucrosum, maltosum, trehalosum, methyl $\alpha$-D-glucosidum, cellobiosum, salicinum, arbutinum, melezitosum (variabilitre), glycerolum, ribitolum, xylitolum (infirme, variabilitre), D-glucitolum, D-mannitolum, gluconolactonum, 2-keto-Dgluconatum, D-gluconatum (variabilitre), acidum succinicum, acidum citricum, ethanolum et propane-1,2-diolum (infirme, variabilitre). Non assimilantur D-sorbosum, D-ribosum, L-arabinosum, D-arabinosum, D-rhamnosum, melibiosum, lactosum, raffinosum, inulinum, amylum solubile, erythritolum, D-arabinitolum, galactitolum, inositolum, D-glucuronatum, DL-acidum lacticum, methanolum, butano-2,3-diolum, acidum quinicum, D-glucaratum et D-galactonatum. Assimilantur ethylaminum, D-lysinum, cadaverinum et glucosaminum (variabilitre). Non assimilantur kali nitratum, sodii nitritum, creatinum, creatininum, imidazolum et D-tryptophanum. Amylum non formatur. Biotinum externum ad crescentiam necessarium est (variabilitre). In temperatura $30^{\circ} \mathrm{C}$ crescit neque $35^{\circ} \mathrm{C}$. Non crescit in medio $10 \mu \mathrm{g} \mathrm{ml}^{-1}$ cycloheximido addito. Typus: NRRL $\mathrm{Y}-27566^{\mathrm{T}}\left(=\mathrm{CBS} 9830^{\mathrm{T}}\right)$, designat stirpem typicum. Isolata a ile coleopterorum (Tritoma sp.; Erotylidae), Athens, GA, USA, depositata in Collectione Culturarum (NRRL), Peoria, IL, USA.

\section{Description of Candida chickasaworum Suh \& Blackwell sp. nov.}

Candida chickasaworum (chic.ka.sa.wo'rum. N.L. m. gen. chickasaworum to commemorate the Chickasaw, native Americans who in earlier times made use of many endemic and introduced southeastern USA plants).

After 7 days growth in $\mathrm{YM}$ broth at $25^{\circ} \mathrm{C}$, cells are globose, subglobose, to fusiform $(2-6 \times 2-8 \mu \mathrm{m})$, and occur singly, in pairs or in short chains (Fig. 2h). Pseudohyphae and septate hyphae may be present. After 7 days on YM agar at $25^{\circ} \mathrm{C}$, colonies are white to cream-coloured, butyrous and smooth with mycelial edge. After 10 days Dalmau plate culture on corn meal agar at $25^{\circ} \mathrm{C}$, elongated pseudohyphae and septate hyphae may be present. Aerobic growth is white to cream-coloured with mycelial margin. No ascospores produced after 6 weeks at $17^{\circ} \mathrm{C}$ from individual strains on YM agar or strains crossed in all combinations on halfstrength cornmeal agar. See Table 2 for a summary of physiological and other characteristics.

The type strain is NRRL Y $-27566^{\mathrm{T}}\left(=\mathrm{CBS} 9830^{\mathrm{T}}\right)$.

\section{Latin diagnosis of Candida choctaworum Suh et Blackwell sp. nov.}

In medio liquido dextrosum et peptonum et extractum levidinis continente post 7 dies ad $25^{\circ} \mathrm{C}$ cellulae vegetativae globosae aut ovoidae $(2-6 \times 2-8 \mu \mathrm{m})$, plerumque globosae et subglobosae, singulae vel binae. Cultura in agaro extramalti et faecis continente post 7 dies ad $25^{\circ} \mathrm{C}$, albida, butyrosa, teres. In agaro farina Zeae maydis confecto post 10 dies ad $25^{\circ} \mathrm{C}$, pseudohyphae et hyphae verae may fiunt. Ascosporae non fiunt. Glucosum, galactosum (variabilitre) et trehalosum fermentantur. Maltosum, methyl $\alpha$-D-glucosidum, sucrosum, melibiosum, lactosum, cellobiosum, melezitosum, raffinosum, inulinum, amylum solubile et D-xylosum non fermentantur. Assimilantur glucosum, galactosum, D-sorbosum, D-glucosaminum, D-ribosum (variabilitre), D-xylosum, L-arabinosum (infirme, variabilitre), D-arabinosum, trehalosum, cellobiosum, salicinum, arbutinum, glycerolum, erythritolum, ribitolum, xylitolum (variabilitre), Darabinitolum (variabilitre), D-glucitolum, D-mannitolum, gluconolactonum, 2-keto-D-gluconatum, D-gluconatum (variabilitre), acidum succinicum, acidum citricum, ethanolum et propane-1,2-diolum (infirme, variabilitre). Non assimilantur D-rhamnosum, sucrosum, maltosum, methyl $\alpha$-D-glucosidum, melibiosum, lactosum, raffinosum, melezitosum, inulinum, amylum solubile, galactitolum, inositolum, D-glucuronatum, DL-acidum lacticum, methanolum, butano-2,3-diolum, acidum quinicum, D-glucaratum et D-galactonatum. Assimilantur ethylaminum, D-lysinum, cadaverinum et glucosaminum (variabilitre). Non assimilantur kali nitratum, sodii nitritum, creatinum, creatininum, imidazolum et D-tryptophanum. Amylum non formatur. Biotinum externum ad crescentiam necessarium est. Augmentum non fiunt in temperatura $40^{\circ} \mathrm{C}$. Crescit in medio $100 \mu \mathrm{g} \mathrm{ml}^{-1}$ cycloheximido addito. Typus: NRRL $\mathrm{Y}-27584^{\mathrm{T}}\left(=\mathrm{CBS} 9831^{\mathrm{T}}\right)$, designat stirpem typicum. Isolata a ile coleopterorum (Neomida bicornis; Tenebrionidae), Baton Rouge, LA, USA, depositata in Collectione Culturarum (NRRL), Peoria, IL, USA.

\section{Description of Candida choctaworum Suh \& Blackwell sp. nov.}

Candida choctaworum (choc.ta.wo'rum. N.L. m. gen. choctaworum to commemorate the Choctaw, native Americans warriors and code-talkers, many of whom were removed from their native lands in the southeastern USA). 
After 7 days growth in $\mathrm{YM}$ broth at $25^{\circ} \mathrm{C}$, cells are globose to oval $(2-6 \times 2-8 \mu \mathrm{m})$, and occur singly, in pairs or in short chains (Fig. 2i). Pseudohyphae may be present. After 7 days on YM agar at $25^{\circ} \mathrm{C}$, colonies are white to creamcoloured, smooth and butyrous with slightly wrinkled edge. After 10 days Dalmau plate culture on corn meal agar at $25^{\circ} \mathrm{C}$, pseudohyphae and septate hyphae may be present. Aerobic growth is white, shiny, smooth and slightly fuzzy. No ascospores produced after 6 weeks at $17^{\circ} \mathrm{C}$ from individual strains on YM agar or strains crossed in all combinations on half-strength cornmeal agar. See Table 2 for a summary of physiological and other characteristics.

The type strain is NRRL Y $-27584^{\mathrm{T}}\left(=\mathrm{CBS} 9831^{\mathrm{T}}\right)$.

\section{Latin diagnosis of Candida bolitotheri Suh et Blackwell sp. nov.}

In medio liquido dextrosum et peptonum et extractum levidinis continente post 7 dies ad $25^{\circ} \mathrm{C}$ cellulae vegetativae globosae aut subglobosae $(2-6 \times 2-6 \mu \mathrm{m})$, singulae vel binae. Pseudohyphae fiunt. Cultura in agaro extramalti et faecis continente post 7 dies ad $25^{\circ} \mathrm{C}$, albida, teres, margine ciliata. In agaro farina Zeae maydis confecto post 10 dies ad $25^{\circ} \mathrm{C}$, pseudohyphae fiunt; hyphae verae fiunt. Ascosporae non fiunt. Glucosum, galactosum et trehalosum fermentantur. Maltosum, methyl $\alpha$-D-glucosidum, sucrosum, melibiosum, lactosum, cellobiosum, melezitosum, raffinosum, inulinum, amylum solubile et D-xylosum non fermentantur. Assimilantur glucosum, galactosum, D-sorbosum (variabilitre), D-glucosaminum, D-ribosum (variabilitre), D-xylosum, trehalosum, cellobiosum, salicinum, arbutinum, glycerolum, erythritolum, ribitolum, xylitolum, D-glucitolum, Dmannitolum, gluconolactonum, 2-keto-D-gluconatum, D-gluconatum (lente, infirme), acidum succinicum, acidum citricum et ethanolum. Non assimilantur L-arabinosum, D-arabinosum, D-rhamnosum, sucrosum, maltosum, methyl $\alpha$-D-glucosidum, melibiosum, lactosum, raffinosum, melezitosum, inulinum, amylum solubile, D-arabinitolum, galactitolum, inositolum, D-glucuronatum, DL-acidum lacticum, methanolum, propane-1,2-diolum, butano-2,3-diolum, acidum quinicum, D-glucaratum et D-galactonatum. Assimilantur ethylaminum, D-lysinum, cadaverinum et glucosaminum. Non assimilantur kali nitratum, sodii nitritum, creatinum, creatininum, imidazolum et D-tryptophanum. Amylum non formatur. Biotinum externum ad crescentiam necessarium est. Augmentum non fiunt in temperatura $45^{\circ} \mathrm{C}$. Variabilitre in medio $10 \mu \mathrm{g} \mathrm{ml}^{-1}$ cycloheximido addito, non crescit in medio $100 \mu \mathrm{g} \mathrm{ml}^{-1}$. Typus: NRRL $\mathrm{Y}-27587^{\mathrm{T}}\left(=\mathrm{CBS} 9832^{\mathrm{T}}\right)$, designat stirpem typicum. Isolata a ile coleopterorum (Bolitotherus cornutus; Tenebrionidae), Athens, GA, USA, depositata in Collectione Culturarum (NRRL), Peoria, IL, USA.

\section{Description of Candida bolitotheri Suh \& Blackwell sp. nov.}

Candida bolitotheri (bo.li.to.the'ri. N.L. n. gen. bolitotheri is named for the coleopteran host, Bolitotherus cornutus, occurring in Ganoderma basidiocarps from Vermont to Louisiana, USA).

After 7 days growth in YM broth at $25^{\circ} \mathrm{C}$, cells are globose to subglobose $(2-6 \times 2-6 \mu \mathrm{m})$, mostly globose, and occur singly or in short chains (Fig. 2j). Pseudohyphae may be present. After 7 days on $\mathrm{YM}$ agar at $25^{\circ} \mathrm{C}$, colonies are white to cream-coloured with very pale-pinkish from centre to edge, and smooth to slightly wrinkled centre with mycelial edge. After 10 days Dalmau plate culture on corn meal agar at $25^{\circ} \mathrm{C}$, pseudohyphae are present. Septate hyphae may be present. Aerobic growth is white, shiny and smooth with filamentous margin. No ascospores produced after 6 weeks at $17^{\circ} \mathrm{C}$ from individual strains on YM agar or strains crossed in all combinations on half-strength cornmeal agar. See Table 2 for a summary of physiological and other characteristics.

The type strain is NRRL Y $-27587^{\mathrm{T}}\left(=\mathrm{CBS} 9832^{\mathrm{T}}\right)$.

\section{Latin diagnosis of Candida atakaporum Suh et Blackwell sp. nov.}

In medio liquido dextrosum et peptonum et extractum levidinis continente post 7 dies ad $25^{\circ} \mathrm{C}$ cellulae vegetativae subglobosae aut cylindratae $(3-5 \times 5-9 \mu \mathrm{m})$, singulae vel binae. Pseudohyphae fiunt. Cultura in agaro extramalti et faecis continente post 7 dies ad $25^{\circ} \mathrm{C}$, albida, butyrosa, margine ciliata. In agaro farina Zeae maydis confecto post 10 dies ad $25^{\circ} \mathrm{C}$, pseudohyphae et hyphae verae fiunt. Ascosporae non fiunt. Glucosum et trehalosum (lente) fermentantur. Galactosum, maltosum, methyl $\alpha$-D-glucosidum, sucrosum, melibiosum, lactosum, cellobiosum, melezitosum, raffinosum, inulinum, amylum solubile et D-xylosum non fermentantur. Assimilantur glucosum, galactosum, D-glucosaminum (lente), D-xylosum, D-arabinosum (infirme), sucrosum, maltosum, trehalosum, methyl $\alpha$-D-glucosidum, cellobiosum, salicinum, arbutinum, melezitosum, amylum solubile (infirme), glycerolum, ribitolum, D-glucitolum, D-mannitolum, gluconolactonum, 2-keto-D-gluconatum, D-gluconatum (infirme), DL-acidum lacticum (lente), acidum succinicum (lente), acidum citricum (lente), ethanolum et propane-1,2-diolum (infirme). Non assimilantur D-sorbosum, D-ribosum, Larabinosum, D-rhamnosum, melibiosum, lactosum, raffinosum, inulinum, erythritolum, xylitolum, D-arabinitolum, galactitolum, inositolum, D-glucuronatum, methanolum, butano-2,3-diolum, acidum quinicum, D-glucaratum et Dgalactonatum. Assimilantur ethylaminum, D-lysinum, cadaverinum, glucosaminum (infirme) et D-tryptophanum (lente). Non assimilantur kali nitratum, sodii nitritum, creatinum, creatininum et imidazolum. Amylum non formatur. Biotinum externum ad crescentiam necessarium est. Augmentum non fiunt in temperatura $40^{\circ} \mathrm{C}$. Non crescit in medio $10 \mu \mathrm{g} \mathrm{ml}{ }^{-1}$ cycloheximido addito. Typus: NRRL Y-27570 ${ }^{\mathrm{T}}$ (=CBS $9833^{\mathrm{T}}$ ), designat stirpem typicum. Isolata a ile coleopterorum (Triplax festiva; Erotylidae), Baton Rouge, LA, USA, depositata in Collectione Culturarum (NRRL), Peoria, IL, USA. 


\section{Description of Candida atakaporum Suh \& Blackwell sp. nov.}

Candida atakaporum (a.ta.ka.po'rum. N.L. m. gen. atakaporum commemorates the Atakapa, native Americans of the northwestern coast of the Gulf of Mexico and their unique language).

After 7 days growth in YM broth at $25^{\circ} \mathrm{C}$, cells are subglobose, ellipsoidal or cylindrical $(3-5 \times 5-9 \mu \mathrm{m})$, and occur singly, in pairs or in short chains (Fig. 2k). Pseudohyphae and septate hyphae may be present. After 7 days on YM agar at $25^{\circ} \mathrm{C}$, colonies are off-white with membranous margin and butyrous with small filamentous spots. After 10 days Dalmau plate culture on corn meal agar at $25^{\circ} \mathrm{C}$, pseudohyphae and septate hyphae are present. Aerobic growth is off-white and fuzzy. No ascospores produced after 6 weeks at $17^{\circ} \mathrm{C}$ from the single strain on YM agar or half-strength cornmeal agar. See Table 2 for a summary of physiological and other characteristics.

The type strain is NRRL Y $-27570^{\mathrm{T}}\left(=\mathrm{CBS} 9833^{\mathrm{T}}\right)$.

\section{Latin diagnosis of Candida panamericana Suh et Blackwell sp. nov.}

In medio liquido dextrosum et peptonum et extractum levidinis continente post 7 dies ad $25^{\circ} \mathrm{C}$ cellulae vegetativae globosae aut ovoidae $(3-6 \cdot 25 \times 3 \cdot 75-7 \mu \mathrm{m})$, plerumque subglobosae, singulae vel binae. Pseudohyphae fiunt. Cultura in agaro extramalti et faecis continente post 7 dies ad $25^{\circ} \mathrm{C}$, albida, teres, margine ciliata. In agaro farina Zeae maydis confecto post 10 dies ad $25^{\circ} \mathrm{C}$, pseudohyphae fiunt; hyphae verae fiunt. Ascosporae non fiunt. Glucosum, galactosum (lente), trehalosum et cellobiosum fermentantur. Maltosum, methyl $\alpha$-D-glucosidum, sucrosum, melibiosum, lactosum, melezitosum, raffinosum, inulinum, amylum solubile et D-xylosum non fermentantur. Assimilantur glucosum, galactosum, D-glucosaminum, D-xylosum, sucrosum, maltosum, trehalosum, methyl $\alpha$-D-glucosidum, cellobiosum, salicinum, arbutinum, melezitosum, glycerolum, ribitolum, D-glucitolum, D-mannitolum, gluconolactonum, 2-keto-Dgluconatum, D-gluconatum, acidum succinicum et acidum citricum. Non assimilantur D-sorbosum, D-ribosum, L-arabinosum, D-arabinosum, D-rhamnosum, melibiosum, lactosum, raffinosum, inulinum, amylum solubile, erythritolum, xylitolum, D-arabinitolum, galactitolum, inositolum, D-glucuronatum, DL-acidum lacticum, methanolum, ethanolum, propane-1,2-diolum, butano-2,3-diolum, acidum quinicum et D-glucaratum. Assimilantur ethylaminum, Dlysinum, cadaverinum et glucosaminum (variabilitre). Non assimilantur kali nitratum, sodii nitritum, creatinum, creatininum, imidazolum et D-tryptophanum. Amylum non formatur. Vitaminae externae ad crescentiam necessaria non sunt. Augmentum non fiunt in temperatura $40^{\circ} \mathrm{C}$. Non crescit in medio $10 \mu \mathrm{g} \mathrm{ml}^{-1}$ cycloheximido addito. Typus: NRRL Y$27567^{\mathrm{T}}$ ( = CBS $9834^{\mathrm{T}}$ ), designat stirpem typicum. Isolata a ile coleopterorum (Mycotretus interstitialis; Erotylidae), Barro
Colorado Island, Panama, depositata in Collectione Culturarum (NRRL), Peoria, IL, USA.

\section{Description of Candida panamericana Suh \& Blackwell sp. nov.}

Candida panamericana (pan.a.mer.i.can'a. N.L. f. adj. panamericana to call attention to its broad distribution spanning the regions from Louisiana to Panama).

After 7 days growth in YM broth at $25^{\circ} \mathrm{C}$, cells are globose to oval $(3-6 \cdot 25 \times 3 \cdot 75-7 \mu \mathrm{m})$, mostly subglobose, and occur singly, in pairs or in short chains (Fig. 21). Some cells form clusters. Pseudohyphae are present. After 7 days on YM agar at $25^{\circ} \mathrm{C}$, colonies are white to off-white in colour, smooth, glistening and flat with filamentous margin. After 10 days Dalmau plate culture on corn meal agar at $25^{\circ} \mathrm{C}$, pseudohyphae are present. Septate hyphae may be present. Aerobic growth is white, shiny and smooth with filamentous margin. No ascospores produced after 6 weeks at $17^{\circ} \mathrm{C}$ from individual strains on YM agar or strains crossed in all combinations on half-strength cornmeal agar. See Table 2 for a summary of physiological and other characteristics.

The type strain is NRRL Y-27567 ${ }^{\mathrm{T}}\left(=\mathrm{CBS} 9834^{\mathrm{T}}\right)$.

\section{Latin diagnosis of Candida bribrorum Suh et Blackwell sp. nov.}

In medio liquido dextrosum et peptonum et extractum levidinis continente post 7 dies ad $25^{\circ} \mathrm{C}$ cellulae vegetativae globosae aut ellipsoideae $(3-8 \times 3-8 \mu \mathrm{m})$, plerumque subglobosae, singulae vel binae. Pseudohyphae fiunt. Cultura in agaro extramalti et faecis continente post 7 dies ad $25^{\circ} \mathrm{C}$, albida, butyrosa, margine ciliata. In agaro farina Zeae maydis confecto post 10 dies ad $25^{\circ} \mathrm{C}$, pseudohyphae et hyphae verae fiunt. Ascosporae non fiunt. Glucosum, galactosum (variabilitre), maltosum (infirme, variabilitre) et trehalosum fermentantur. Methyl $\alpha$-D-glucosidum, sucrosum, melibiosum, lactosum, cellobiosum, melezitosum, raffinosum, inulinum, amylum solubile et D-xylosum non fermentantur. Assimilantur glucosum, galactosum, D-sorbosum (variabilitre), D-glucosaminum, D-ribosum (variabilitre), D-xylosum, L-arabinosum (variabilitre), Darabinosum (variabilitre), sucrosum, maltosum, trehalosum, methyl $\alpha$-D-glucosidum, cellobiosum, salicinum, arbutinum, melezitosum, glycerolum, erythritolum, ribitolum, xylitolum, D-glucitolum, D-mannitolum, gluconolactonum, 2-keto-Dgluconatum, D-gluconatum, acidum succinicum, acidum citricum, ethanolum et propane-1,2-diolum (variabilitre). Non assimilantur D-rhamnosum, melibiosum, lactosum, raffinosum, inulinum, amylum solubile, D-arabinitolum, galactitolum, inositolum, D-glucuronatum, DL-acidum lacticum, methanolum, butano-2,3-diolum, acidum quinicum, D-glucaratum et D-galactonatum. Assimilantur ethylaminum, D-lysinum, cadaverinum et glucosaminum (variabilitre). Non assimilantur kali nitratum, sodii nitritum, creatinum, creatininum, imidazolum et D-tryptophanum. Amylum non 
formatur. Biotinum externum ad crescentiam necessarium est. Augmentum non fiunt in temperatura $40{ }^{\circ} \mathrm{C}$. Infirme crescit in medio $10 \mu \mathrm{g} \mathrm{ml}^{-1}$ cycloheximido addito, variabilitre in $100 \mu \mathrm{g} \mathrm{ml}^{-1}$. Typus: NRRL Y-27572 ${ }^{\mathrm{T}}\left(=\mathrm{CBS} 9835^{\mathrm{T}}\right)$, designat stirpem typicum. Isolata a ile coleopterorum (Pselaphacus sp.; Erotylidae), Barro Colorado Island, Panama, depositata in Collectione Culturarum (NRRL), Peoria, IL, USA.

\section{Description of Candida bribrorum Suh \& Blackwell sp. nov.}

Candida bribrorum (bri.bro'rum. N.L. m. gen. bribrorum to commemorate the Bribri, a small group of indigenous people of northern Panama, who apply ecological principles and recognize symbiotic relationships).

After 7 days growth in YM broth at $25^{\circ} \mathrm{C}$, cells are globose to ellipsoidal (3-8 $\times 3-8 \mu \mathrm{m})$, mostly subglobose, and occur singly, in pairs or in short chains (Fig. 3a). Pseudohyphae are present. After 7 days on YM agar at $25^{\circ} \mathrm{C}$, colonies are white to cream in colour, butyrous and smooth surface with slightly fuzzy spots. After 10 days Dalmau plate culture on corn meal agar at $25^{\circ} \mathrm{C}$, pseudohyphae and septate hyphae are present. Aerobic growth is white to cream-coloured with fuzzy margin. No ascospores produced after 6 weeks at $17^{\circ} \mathrm{C}$ from individual strains on YM agar or strains crossed in all combinations on half-strength

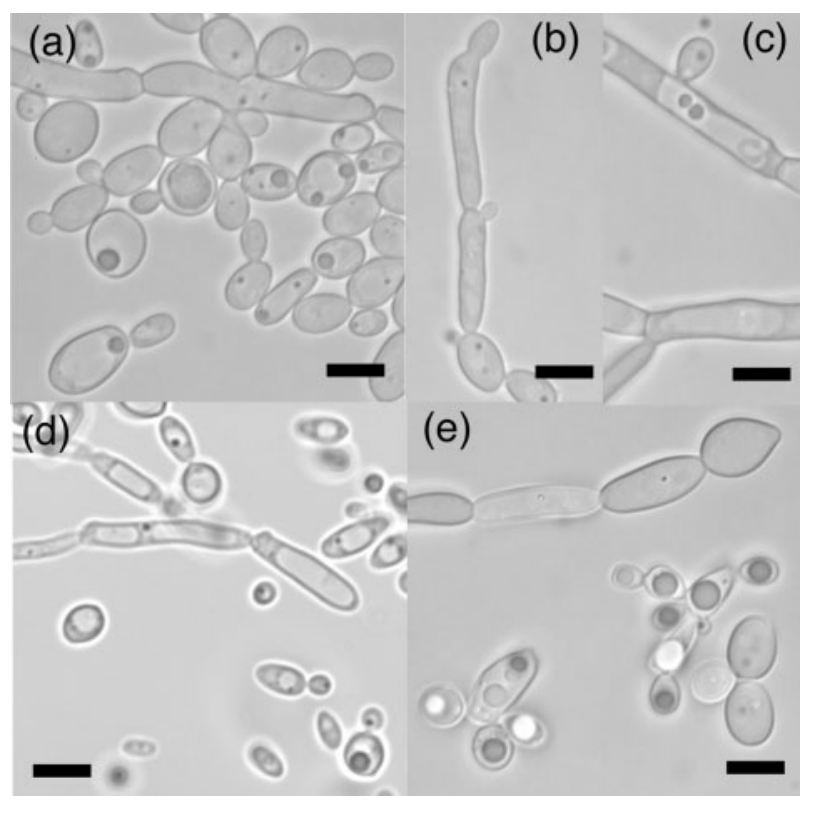

Fig. 3. Budding yeast cells, pseudohyphae and septate hyphae of the novel species. (a) C. bribrorum NRRL Y-27572 ${ }^{\top}$; (b, c) C. maxii NRRL Y-27588' ; (d) yeast cells of C. anneliseae NRRL Y-27563 ${ }^{\top}$; (e) C. taliae NRRL Y-27589 ${ }^{\top}$. (a-c) Seven days, YM broth, $25^{\circ} \mathrm{C}$; (d, e) 7 days, half-strength cornmeal agar, $25^{\circ} \mathrm{C}$. Bars, $5 \mu \mathrm{m}$. cornmeal agar. See Table 2 for a summary of physiological and other characteristics.

The type strain is NRRL Y $-27572^{\mathrm{T}}\left(=\mathrm{CBS} 9835^{\mathrm{T}}\right)$.

\section{Latin diagnosis of Candida maxii Suh et Blackwell sp. nov.}

In medio liquido dextrosum et peptonum et extractum levidinis continente post 7 dies ad $25^{\circ} \mathrm{C}$ cellulae vegetativae globosae aut subglobosae $(2-6 \cdot 25 \times 3 \cdot 75-6 \cdot 25 \mu \mathrm{m})$, singulae vel binae. Pseudohyphae et hyphae verae fiunt. Cultura in agaro extramalti et faecis continente post 7 dies ad $25^{\circ} \mathrm{C}$, albida, margine ciliata. In agaro farina Zeae maydis confecto post 10 dies ad $25^{\circ} \mathrm{C}$, pseudohyphae et hyphae verae fiunt. Ascosporae non fiunt. Glucosum (lente), trehalosum (infirme) et cellobiosum (infirme) fermentantur. Galactosum, maltosum, methyl $\alpha$-D-glucosidum, sucrosum, melibiosum, lactosum, melezitosum, raffinosum, inulinum, amylum solubile et D-xylosum non fermentantur. Assimilantur glucosum, galactosum, D-glucosaminum (lente), D-ribosum, D-arabinosum (infirme), sucrosum, maltosum, trehalosum, methyl $\alpha$-Dglucosidum, cellobiosum, salicinum, arbutinum, melezitosum, glycerolum (lente), erythritolum, ribitolum, xylitolum (infirme), D-glucitolum, D-mannitolum, gluconolactonum (lente), 2-keto-D-gluconatum, D-gluconatum, acidum succinicum, acidum citricum et ethanolum. Non assimilantur D-sorbosum, D-xylosum, L-arabinosum, D-rhamnosum, melibiosum, lactosum, raffinosum, inulinum, amylum solubile, D-arabinitolum, galactitolum, inositolum, D-glucuronatum, DL-acidum lacticum, methanolum, propane-1,2-diolum, butano-2,3-diolum, acidum quinicum, D-glucaratum et D-galactonatum. Assimilantur ethylaminum, D-lysinum, cadaverinum et glucosaminum (infirme). Non assimilantur kali nitratum, sodii nitritum, creatinum, creatininum, imidazolum et D-tryptophanum. Amylum non formatur. Biotinum externum ad crescentiam necessarium est. $30^{\circ} \mathrm{C}$ crescit neque $35^{\circ} \mathrm{C}$. Non crescit in medio $10 \mu \mathrm{g} \mathrm{ml}^{-1}$ cycloheximido addito. Typus: NRRL Y-27588 ${ }^{\mathrm{T}}$ (=CBS $9836^{\mathrm{T}}$ ), designat stirpem typicum. Isolata a ile coleopterorum (Tenebrionidae), Barro Colorado Island, Panama, depositata in Collectione Culturarum (NRRL), Peoria, IL, USA.

\section{Description of Candida maxii Suh \& Blackwell sp. nov.}

Candida maxii (max.i'i. N.L. m. gen. maxii for Max Vallone, whose grandparents generously support the Mycological Society of America).

After 7 days growth in YM broth at $25^{\circ} \mathrm{C}$, cells are globose to subglobose $(2 \cdot 5-6 \cdot 25 \times 3 \cdot 75-6 \cdot 25 \mu \mathrm{m})$. Pseudohyphae and septate hyphae are present (Fig. 3b, c). After 7 days on YM agar at $25^{\circ} \mathrm{C}$, colonies are white in colour, ridged, glistening and flat with filamentous margin. After 10 days Dalmau plate culture on corn meal agar at $25^{\circ} \mathrm{C}$, pseudohyphae and septate hyphae are present. Aerobic growth is white, shiny and smooth with filamentous margin. No ascospores produced after 6 weeks at $17^{\circ} \mathrm{C}$ from individual 
strains on YM agar or strains crossed in all combinations on half-strength cornmeal agar. See Table 2 for a summary of physiological and other characteristics.

The type strain is NRRL Y $-27588^{\mathrm{T}}\left(=\mathrm{CBS} 9836^{\mathrm{T}}\right)$.

\section{Latin diagnosis of Candida anneliseae Suh et Blackwell sp. nov.}

In medio liquido dextrosum et peptonum et extractum levidinis continente post 7 dies ad $25^{\circ} \mathrm{C}$ cellulae vegetativae globosae aut ellipsoideae $(1 \cdot 25-7 \times 1 \cdot 25-7 \mu \mathrm{m})$, singulae vel binae. Pseudohyphae fiunt. Cultura in agaro extramalti et faecis continente post 7 dies ad $25^{\circ} \mathrm{C}$, albida, teres, margine ciliata. In agaro farina Zeae maydis confecto post 10 dies ad $25^{\circ} \mathrm{C}$, pseudohyphae fiunt, hyphae verae fiunt. Ascosporae non fiunt. Glucosum et trehalosum (lente, infirme) fermentantur. Galactosum, maltosum, methyl $\alpha$-D-glucosidum, sucrosum, melibiosum, lactosum, cellobiosum, melezitosum, raffinosum, inulinum, amylum solubile et D-xylosum non fermentantur. Assimilantur glucosum, galactosum (variabilitre), D-sorbosum (variabilitre), D-glucosaminum, D-ribosum (variabilitre), D-xylosum, D-arabinosum, sucrosum, maltosum, trehalosum, methyl $\alpha$-D-glucosidum, cellobiosum, salicinum, arbutinum, melezitosum, glycerolum, erythritolum, ribitolum, xylitolum, D-arabinitolum (variabilitre), D-glucitolum, D-mannitolum, gluconolactonum, 2-keto-D-gluconatum, D-gluconatum, acidum succinicum, acidum citricum, ethanolum et propane-1,2-diolum (infirme, variabilitre). Non assimilantur L-arabinosum, Drhamnosum, melibiosum, lactosum, raffinosum, inulinum, amylum solubile, galactitolum, inositolum, D-glucuronatum, DL-acidum lacticum, methanolum, butano-2,3-diolum, acidum quinicum, D-glucaratum et D-galactonatum. Assimilantur ethylaminum, D-lysinum, cadaverinum et glucosaminum (variabilitre). Non assimilantur kali nitratum, sodii nitritum, creatinum, creatininum, imidazolum et D-tryptophanum. Amylum non formatur. Biotinum externum ad crescentiam necessarium est. Augmentum non fiunt in temperatura $40{ }^{\circ} \mathrm{C}$. Variabilitre in medio $10 \mu \mathrm{g} \mathrm{ml} \mathrm{m}^{-1}$ cycloheximido addito, non crescit in medio $100 \mu \mathrm{g} \mathrm{ml} \mathrm{m}^{-1}$. Typus: NRRL Y-27563 ${ }^{\mathrm{T}}\left(=\mathrm{CBS} 9837^{\mathrm{T}}\right)$, designat stirpem typicum. Isolata a ile coleopterorum (Megalodacne fasciata; Erotylidae), Athens, GA, USA, depositata in Collectione Culturarum (NRRL), Peoria, IL, USA.

\section{Description of Candida anneliseae Suh \& Blackwell sp. nov.}

Candida anneliseae (an.ne.lis.e' ae N.L. n. gen. anneliseae for Annelise Berler, whose grandparents generously support the Mycological Society of America).

After 7 days growth in YM broth at $25^{\circ} \mathrm{C}$, cells are globose to ellipsoid $(1 \cdot 25-7 \times 1 \cdot 25-7 \mu \mathrm{m})$, and occur singly, in pairs or in chains (Fig. 3d). Pseudohyphae may be present. After 7 days on YM agar at $25^{\circ} \mathrm{C}$, colonies are white to creamcoloured, pale-pinkish from centre to edge and smooth with slightly winkled mycelial edge. After 10 days Dalmau plate culture on corn meal agar at $25^{\circ} \mathrm{C}$, pseudohyphae are present. Septate hyphae may be present. Aerobic growth is white, shiny, smooth, and the growth consistent throughout mycelium with filamentous-like periphery. No ascospores produced after 6 weeks at $17^{\circ} \mathrm{C}$ from individual strains on YM agar or strains crossed in all combinations on halfstrength cornmeal agar. See Table 2 for a summary of physiological and other characteristics.

The type strain is NRRL Y $-27563^{\mathrm{T}}\left(=\mathrm{CBS} 9837^{\mathrm{T}}\right)$.

\section{Latin diagnosis of Candida taliae Suh et Blackwell sp. nov.}

In medio liquido dextrosum et peptonum et extractum levidinis continente post 7 dies ad $25^{\circ} \mathrm{C}$ cellulae vegetativae globosae aut ovoidae $(2 \cdot 5-5 \times 3 \cdot 75-6 \cdot 25 \mu \mathrm{m})$, plerumque ellipsoideae, singulae vel binae. Pseudohyphae et hyphae verae fiunt. Cultura in agaro extramalti et faecis continente post 7 dies ad $25^{\circ} \mathrm{C}$, albida, butyrosa, teres, margine ciliata. In agaro farina Zeae maydis confecto post 10 dies ad $25^{\circ} \mathrm{C}$, pseudohyphae fiunt; hyphae verae non fiunt. Ascosporae non fiunt. Glucosum, galactosum (lente) trehalosum (lente) et cellobiosum (lente) fermentantur. Maltosum, methyl $\alpha$-D-glucosidum, sucrosum, melibiosum, lactosum, melezitosum, raffinosum, inulinum, amylum solubile et D-xylosum non fermentantur. Assimilantur glucosum, galactosum, D-glucosaminum, D-xylosum (lente), D-arabinosum, sucrosum, maltosum, trehalosum, methyl $\alpha$-D-glucosidum, cellobiosum, salicinum, arbutinum, melezitosum, glycerolum, erythritolum, ribitolum, xylitolum (lente), D-glucitolum, Dmannitolum, gluconolactonum (lente), 2-keto-D-gluconatum, D-gluconatum, acidum succinicum, acidum citricum et ethanolum. Non assimilantur D-sorbosum, D-ribosum, L-arabinosum, D-rhamnosum, melibiosum, lactosum, raffinosum, inulinum, amylum solubile, D-arabinitolum, galactitolum, inositolum, D-glucuronatum, DL-acidum lacticum, methanolum, propane-1,2-diolum, butano-2,3-diolum, acidum quinicum, D-glucaratum et D-galactonatum. Assimilantur ethylaminum, D-lysinum, cadaverinum et glucosaminum (infirme). Non assimilantur kali nitratum, sodii nitritum, creatinum, creatininum, imidazolum et Dtryptophanum. Amylum non formatur. Biotinum externum ad crescentiam necessarium est. Augmentum non fiunt in temperatura $40^{\circ} \mathrm{C}$. Non crescit in medio $10 \mu \mathrm{g} \mathrm{ml}^{-1}$ cycloheximido addito. Typus: NRRL Y $-27589^{\mathrm{T}}$ (=CBS $\left.9838^{\mathrm{T}}\right)$, designat stirpem typicum. Isolata a ile coleopterorum (Tenebrionidae), Barro Colorado Island, Panama, depositata in Collectione Culturarum (NRRL), Peoria, IL, USA.

\section{Description of Candida taliae Suh \& Blackwell sp. nov.}

Candida taliae (tal'i.ae. N.L. n. gen. taliae for Talia Berler, whose grandparents generously support the Mycological Society of America).

After 7 days growth in $\mathrm{YM}$ broth at $25^{\circ} \mathrm{C}$, cells are globose to oval $(2 \cdot 5-5 \times 3 \cdot 75-6 \cdot 25 \mu \mathrm{m})$, mostly ellipsoidal, and 
occur singly, in pairs or in short chains (Fig. 3e). Pseudohyphae and septate hyphae are present. After 7 days on YM agar at $25^{\circ} \mathrm{C}$, colonies are off-white, butyrous and mostly smooth with bumpy areas in centre. After 10 days Dalmau plate culture on corn meal agar at $25^{\circ} \mathrm{C}$, pseudohyphae are present; septate hyphae are absent. Aerobic growth is white, shiny and smooth with filamentous margin. No ascospores produced after 6 weeks at $17^{\circ} \mathrm{C}$ from the single strain on YM agar or half-strength cornmeal agar. See Table 2 for a summary of physiological and other characteristics.

The type strain is NRRL Y-27589 $\left(=\right.$ CBS $\left.9838^{\mathrm{T}}\right)$.

\section{Gut yeasts close to Candida ambrosiae Kurtzman (Table 1)}

After 7 days growth in YM broth at $25{ }^{\circ} \mathrm{C}$, cells are globose to ellipsoidal $(2 \cdot 5-5 \times 2 \cdot 5-6 \cdot 25 \mu \mathrm{m})$, and occur singly, in pairs or in chains. Pseudohyphae are present. After 7 days on YM agar at $25^{\circ} \mathrm{C}$, colonies are white to cream-coloured, rough and partly powdery with wrinkled mycelial edge. After 10 days Dalmau plate culture on corn meal agar at $25^{\circ} \mathrm{C}$, pseudohyphae are present. Aerobic growth is white, dull, dry, powdery; consistent growth throughout mycelium with branch-like periphery. No ascospores produced after 6 weeks at $17^{\circ} \mathrm{C}$ from individual strains on YM agar or strains crossed in all combinations on halfstrength cornmeal agar. See Table 2 for a summary of physiological and other characteristics.

\section{CT clade: a major clade of gut yeasts from basidiocarp-feeding beetles}

The repeated isolation of $C$. tanzawaensis-like yeasts from beetles first attracted our attention to these fungi. As mentioned above, about $30 \%$ of all 650 yeast isolates from our ongoing study are members of the clade. Except for a few isolates we placed in C. ambrosiae, none had been described previously (Fig. 1). Most of the 16 novel CT clade members appear to be common associates of basidiocarpfeeding beetles, and some of the yeasts have broad geographical distributions. The 22-year interval between the isolation of C. tanzawaensis and its description, and the absence of any additional reports in the intervening 21 years since the description (Nakase et al., 1988), contrasts with the common occurrence of the novel CT yeasts and C. ambrosiae in the specialized gut habitat in which we have found them thus far. The discovery of so many novel species of undescribed yeasts suggests that the microbial flora of the beetle gut is distinctive and has not been well examined previously. We do not know the basis of the apparent widespread relationship between these organisms, but it must be significant to beetles or yeasts or both because the associations are so common. In one case an unsuspected genetic resource that might be tied to such a function has been suggested for a yeast associate of certain wood-ingesting beetles (Suh et al., 2003).

\section{Host specificity of yeasts and dispersal in the CT clade}

Our data reveal several examples of highly specific associations between certain beetles and yeasts. The same yeast was associated repeatedly with Neomida bicornis (Tenebrionidae); this yeast (Tene1 of C. choctaworum) was isolated from the beetle gut at least eight times from five different localities in southern Louisiana over a 5-year period (Table 1). Another specialized association occurred between Bolitotherus cornutus (Tenebrionidae) and Tene11 of $C$. bolitotheri in all samples examined from Vermont to southwestern Louisiana (Table 1). We also observed that several CT clade yeasts were present in the gut of insects at different stages in the insect life histories. For example, Erot38 (C. bribrorum) has been found in both a pupa and an adult of Megalodacne audouini, and Mela2 ( $C$. anneliseae) was isolated from larvae and adults of the same melandreid beetle species. Our indirect evidence, therefore, supports a view that certain yeasts are present during the entire life cycle of their beetle hosts and that parental transmission occurs early in successive generations (Suh \& Blackwell, 2004). Previous studies have shown maternal transmission of yeasts to insects, including examples such as the yeast-like endosymbionts of anobiid beetles that are transmitted to their offspring by contamination of the egg shell (Jurzitza, 1979).

Several beetle species in the Tenebrionidae are associated with closely related yeasts. An example of a close association is Tene4 (C. anneliseae), isolated from species of Diaperis, Neomida, Platydema, Alobates and several unidentified taxa. These yeasts have identical D1/D2 genotypes and small, but consistent, differences in physiological traits to distinguish among them. Other CT clade yeasts also show evidence of past host-switching among distantly related beetles. For example, isolates of $C$. anneliseae (Mela2, Hist5 and Ciid5) are identical to Tene4 in D1/D2 genotype, although the beetle hosts are not closely related and belong to four different families spread throughout a broad geographical range in our sampling. We will need to investigate the possibility of more variable DNA markers to explain transmission among phylogenetically distinct hosts. We believe that these beetles most likely acquired their yeast associates comparatively recently, perhaps by relatively rare host-switching within a common habitat.

\section{Diversification and resolution of taxa within the CT clade}

Identification of yeast taxa based on morphological and physiological characteristics has been problematic and often leads to misidentification (Kurtzman \& Phaff, 1987; Price et al., 1978). For this reason molecular methods increasingly are being used to identify yeasts; additionally, molecular markers, especially DNA sequences, have become the standard for the description of yeast species. The variable D1/D2 sequence of the LSU rRNA gene (about $600 \mathrm{bp}$ ) has been determined for currently recognized ascomycete yeasts 
(Kurtzman \& Robnett, 1995, 1997, 1998; Suh \& Blackwell, 2004). In addition to helping to delimit species, comparisons of the D1/D2 sequences also are a useful tool for rapid identification of yeasts and detection of novel species (e.g. Kurtzman, 2000) with a few exceptions among closely related species, such as Saccharomyces bayanus and Saccharomyces pastorianus (Kurtzman \& Robnett, 1998).

In our study, SSU rRNA gene sequences, as expected, did not provide enough variation to distinguish all species in the CT clade. Identical sequences were determined for about $1750 \mathrm{bp}$ of the SSU rRNA gene for three pairs of taxa: C. tanzawaensis and C. ambrosiae, C. guaymorum and C. bokatorum, and C. maxii and C. anneliseae. The more variable D1/D2 loop sequences of the LSU rRNA gene, which sometimes may be too variable to align among phylogenetically distant groups when comparing a broad range of yeasts, were useful in distinguishing CT clade yeasts (Suh et al., 2004). The differences in D1/D2 sequences, varying from 6 to more than 60 bp between species and less than $3 \mathrm{bp}$ for multiple isolates of a species, revealed some close relationships. For example, the strains Endo2 and Erot 24 in C. emberorum are only 3 bp different in D1/D2 region, and there are only minor differences within the species of $C$. panamericana and C. bribrorum in that region (Table 1 ). The closely related CT clade yeasts additionally were supported by other taxonomic characters, and more than 80 physiological tests have been useful in distinguishing the taxa (Table 2). In addition to identification of CT clade species using BLAST searches and phylogenetic analyses based on DNA, identification was possible using physiological traits.

\section{ACKNOWLEDGEMENTS}

We thank Louisiana State University undergraduate students Christine Ackerman, Katie Brillhart, Cennet Erbil, Nhu Nguyen, Ebony Spikes and Amy Whittington for their skilled assistance in all phases of this study. Dr Donald Windsor, Dr Annette Aiello, Ms Oris Acevedo and Ms Maria Leone graciously provided information and helped with logistics for collecting at the Smithsonian Tropical Research Institute, Barro Colorado Island, Panama. Drs Jean Euzéby and Richard Warga gave expert advice on Latin names and descriptions. We acknowledge the curators and culture collections that preserve the germ plasm derived from and used in our studies: NRRL, CBS and ATCC. Use of the GenBank public database also is acknowledged. The work was supported by the National Science Foundation, Biodiversity Surveys and Inventories Program (DEB-0072741) and by the Louisiana State University Boyd Professor Fund.

\section{REFERENCES}

Barnett, J. A., Payne, R. W. \& Yarrow, D. (2000). Yeasts: Characteristics and Identification, 3rd edn. Cambridge: Cambridge University Press.

Hausner, G., Reid, J. \& Klassen, G. R. (1993). On the subdivision of Ceratocystis s.l., based on partial ribosomal DNA sequences. Can J Bot 71, 52-63.
Jones, K. G. \& Blackwell, M. (1996). Ribosomal DNA sequence analysis places the yeast-like genus Symbiotaphrina within filamentous ascomycetes. Mycologia 88, 212-218.

Jones, K. G., Dowd, P. F. \& Blackwell, M. (1999). Polyphyletic origins of yeast-like endocytobionts from anobiid and cerambycid beetles. Mycol Res 103, 542-546.

Jurzitza, G. (1979). The fungi symbiotic with anobiid beetles. In Insect-Fungus Symbiosis: Nutrition, Mutualism, and Commensalism, pp. 65-76. Edited by L. R. Batra. New York: Wiley.

Kurtzman, C. P. (2000). Four new yeasts in the Pichia anomala clade. Int J Syst Evol Microbiol 50, 395-404.

Kurtzman, C. P. (2001). Six new anamorphic ascomycetous yeasts near Candida tanzawaensis. FEMS Yeast Res 1, 177-185.

Kurtzman, C. P. \& Phaff, H. J. (1987). Molecular taxonomy. In The Yeasts, vol. 1, Biology of Yeasts, pp. 63-94. Edited by A. H. Rose \& J. S. Harrison. London: Academic Press.

Kurtzman, C. P. \& Robnett, C. J. (1995). Molecular relationships among hyphal ascomycetous yeasts and yeastlike taxa. Can J Bot 73, S824-S830.

Kurtzman, C. P. \& Robnett, C. J. (1997). Identification of clinically important ascomycetous yeasts based on nucleotide divergence in the $5^{\prime}$ end of the large subunit (26S) ribosomal DNA gene. J Clin Microbiol 35, 1216-1223.

Kurtzman, C. P. \& Robnett, C. J. (1998). Identification and phylogeny of ascomycetous yeasts from analysis of nuclear large subunit (26S) ribosomal DNA partial sequences. Antonie Van Leeuwenhoek 73, 331-371.

Lee, S. B. \& Taylor, J. W. (1990). Isolation of DNA from fungal mycelia and single spores. In PCR Protocols - a Guide to Methods and Applications, pp. 282-287. Edited by M. A. Innis, D. H. Gelfand, J. J. Sninsky \& T. J. White. San Diego, CA: Academic Press.

Nakase, T., Itoh, M., Takematsu, A. \& Komagata, K. (1988). Candida tanzawaensis, a new species of yeast isolated from moss collected in Japan. Trans Mycol Soc Jpn 29, 331-338.

Nardon, P. \& Grenier, A. M. (1989). Endosymbiosis in Coleoptera: biological, biochemical, and genetic aspects. In Insect Endocytobiosis: Morphology, Physiology, Genetics, Evolution, pp. 175-216. Edited by W. Schwemmler \& G. Gassner. Boca Raton, FL: CRC Press.

Noda, H. \& Kodama, K. (1996). Phylogenetic position of yeastlike endosymbionts of anobiid beetles. Appl Environ Microbiol 62, 162-167.

Noda, H. \& Omura, T. (1992). Purification of yeast-like symbiotes of planthoppers. J Invertebr Pathol 59, 104-105.

Noda, H., Nakashima, N. \& Koizumi, M. (1995). Phylogenetic position of yeast-like symbiotes of rice planthoppers based on partial $18 \mathrm{~S}$ rDNA sequences. Insect Biochem Mol Biol 25, 639-646.

Price, C. W., Fuson, G. B. \& Phaff, H. J. (1978). Genome comparison in yeast systematics: delimination of species within the genera Schwanniomyces, Saccharomyces, Debaryomyces and Pichia. Microbiol Rev 42, 161-193.

Suh, S.-O. \& Blackwell, M. (2004). The beetle gut as a habitat for new species of yeasts. In Insect Fungal Associations: Ecology and Evolution, (in press). Edited by F. E. Vega \& M. Blackwell. New York: Oxford University Press.

Suh, S.-O., Noda, H. \& Blackwell, M. (2001). Insect symbiosis: derivation of yeast-like endosymbionts within an entomopathogenic filamentous lineage. Mol Biol Evol 18, 995-1000.

Suh, S.-O., Marshall, C. J., McHugh, J. V. \& Blackwell, M. (2003). Wood ingestion by passalid beetles in the presence of xylosefermenting gut yeasts. Mol Ecol 12, 3137-3145.

Suh, S.-O., McHugh, J. V. \& Blackwell, M. (2004). Metschnikowia chrysoperlae sp. nov., Candida picachoensis sp. nov. and Candida 
pimensis sp. nov., isolated from the green lacewings Chrysoperla comanche and Chrysoperla carnea (Neuroptera: Chrysopidae). Int J Syst Evol Microbiol 54, 1883-1890.

Swofford, D. L. (2002). PAUP*. Phylogenetic Analysis Using Parsimony ( ${ }^{*}$ and Other Methods), version 4.0b10. Sunderland, MA: Sinauer Associates.

Tatusova, T. A. \& Madden, T. L. (1999). BLAST 2 Sequences, a new tool for comparing protein and nucleotide sequences. FEMS Microbiol Lett 174, 247-250.

Thompson, J. D., Gibson, T. J., Plewniak, F., Jeanmougin, F. \& Higgins, D. G. (1997). The CLUSTAL_X windows interface: flexible strategies for multiple sequence alignment aided by quality analysis tools. Nucleic Acids Res 25, 4876-4882.

White, T. J., Bruns, T., Lee, S. \& Taylor, J. (1990). Amplification and direct sequencing of fungal ribosomal RNA genes for phylogenetics. In PCR Protocols - a Guide to Methods and Applications, pp. 315-322. Edited by M. A. Innis, D. H. Gelfand, J. J. Sninsky \& T. J. White. San Diego, CA: Academic Press.

Yarrow, D. (1998). Methods for the isolation, maintenance and identification of yeasts. In The Yeasts, a Taxonomic Study, 4th edn, pp. 77-100. Edited by C. P. Kurtzman \& J. W. Fell. Amsterdam: Elsevier. 